\title{
A qualitative evaluation of a co-responding mobile crisis intervention team in a small
} Canadian police service

\author{
by
}

Jamie Thompson

A thesis submitted to the Faculty of Graduate and Postdoctoral Affairs in partial fulfillment of the requirements for the degree of

\author{
Master of Arts \\ in \\ Psychology \\ Carleton University \\ Ottawa, Ontario
}

(C) 2020

Jamie Thompson 


\begin{abstract}
Mobile Crisis Intervention Teams (MCITs) are meant to assist the police in responding appropriately to calls involving persons in crisis with the goal of providing short-term crisis management, as well as open doors to available resources for long-term support. Many police agencies across North America have implemented a MCIT, however, evaluations of these programs are limited. This thesis presents a qualitative evaluation of the South Simcoe Police Services' (SSPS) Crisis Outreach and Support Team (COAST) located in Bradford, Ontario. The COAST is based on the MCIT model and builds on a partnership between SSPS and two mental health organizations within the community (Canadian Mental Health Association [CMHA] and York Support Service Network [YSSN]). The evaluation consisted of interviews with various stakeholder groups including COAST members, SSPS senior leaders and frontline officers, and senior leaders from YSSN and CMHA, Barrie. Throughout the interviews, it became clear that there was a great need for the COAST in South Simcoe due to the increasing number of crisis calls in which the police were required to respond. There was strong consensus among stakeholders that the COAST provides a better service than a conventional police response to those experiencing crises while also helping to bridge the gap between the police and mental health care providers who traditionally work in silos. Despite the perceived benefits of the COAST, the lack of resources was seen as a major challenge. That being said, the current findings still suggest that co-responding teams may improve the way the police respond to individuals in crisis.
\end{abstract}

Keywords: mobile crisis intervention team, mental health, police, qualitative research 


\section{Table of Contents}

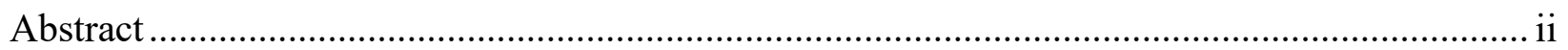

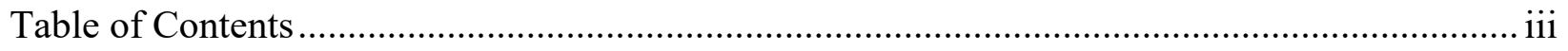

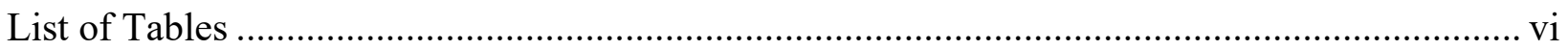

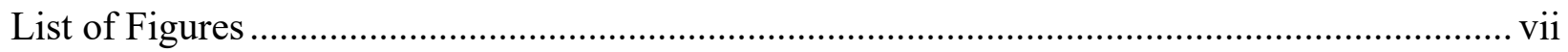

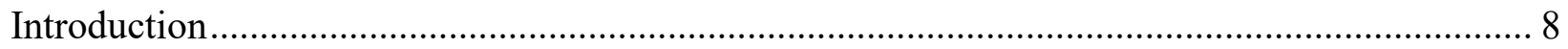

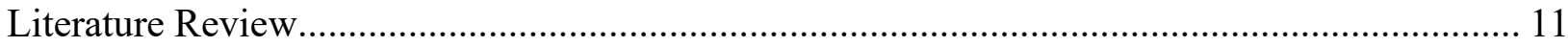

Mental Illness and the Criminal Justice System.......................................................... 11

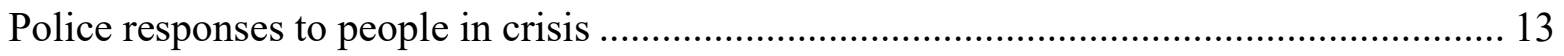

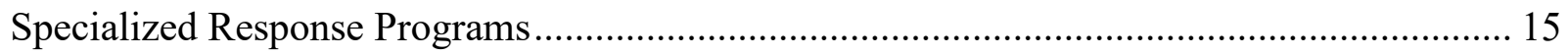

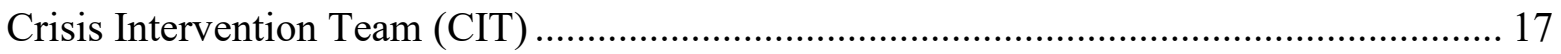

Mobile Crisis Intervention Team (MCIT) ................................................................... 19

South Simcoe Police Service's COAST Program ............................................................... 22

SSPS COAST Logic Model ...................................................................................... 23

The Initial Quantitative Evaluation ............................................................................. 29

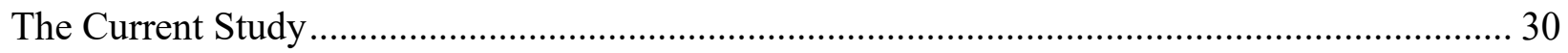

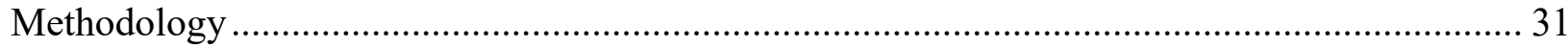

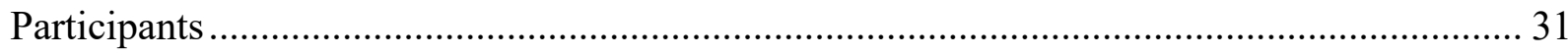

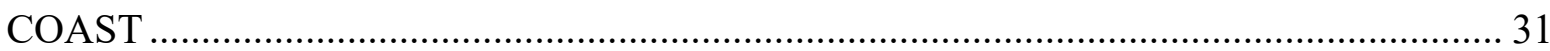

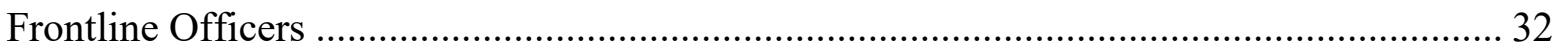




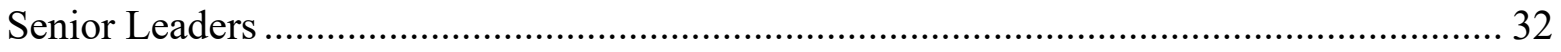

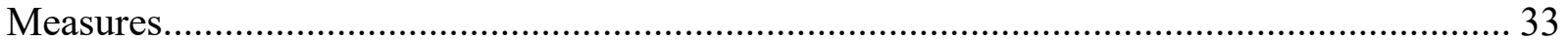

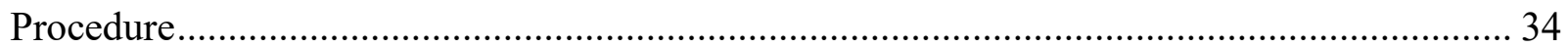

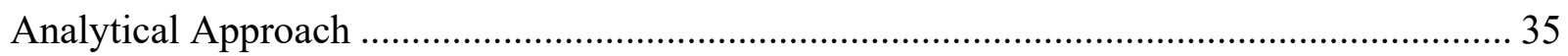

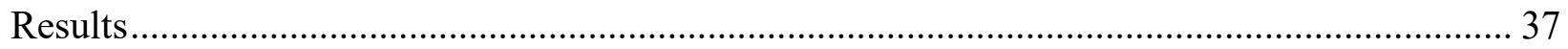

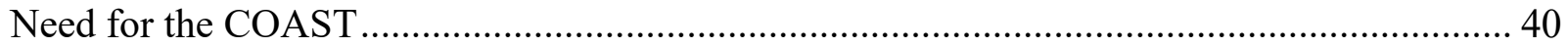

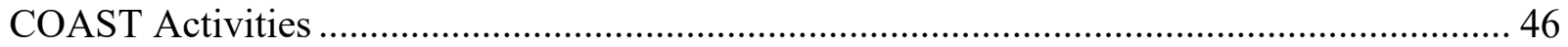

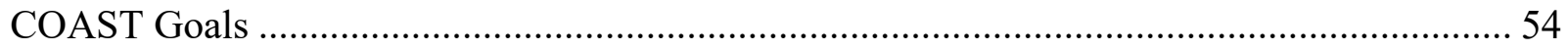

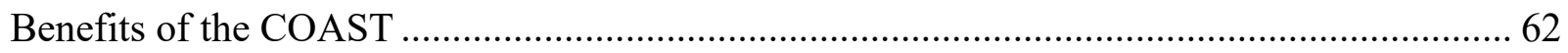

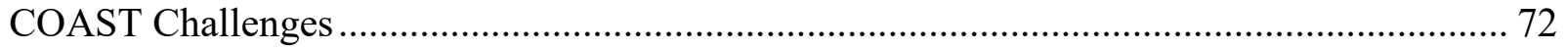

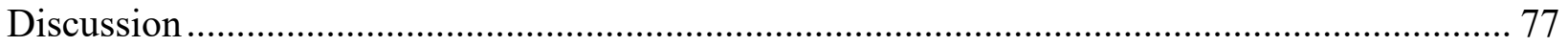

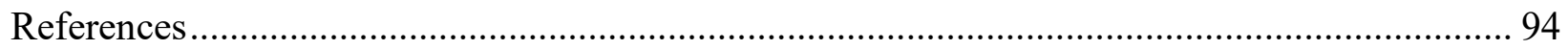

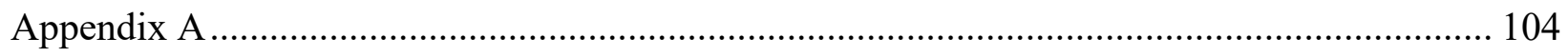

Interview Questions: COAST Team Members ............................................................. 104

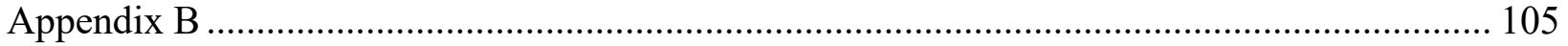

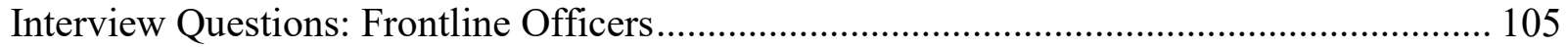

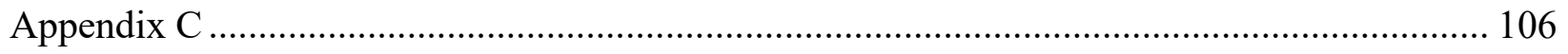

Interview Questions: Senior Leaders ................................................................... 106

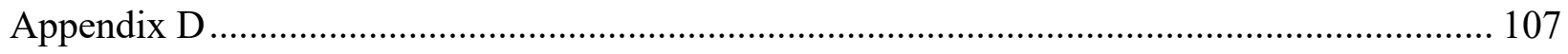

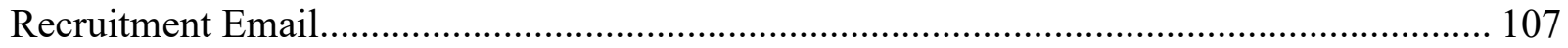




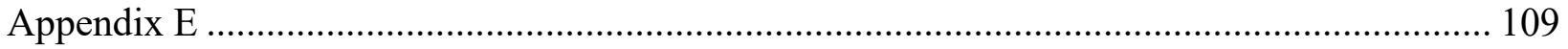

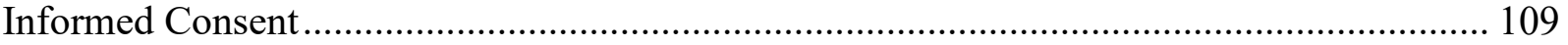

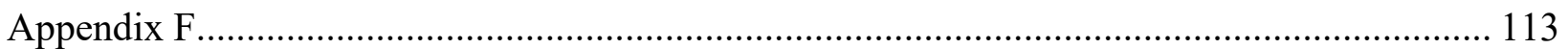

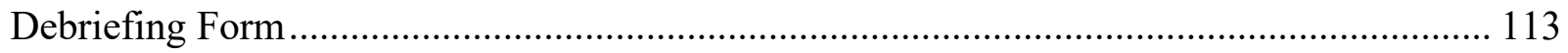

Appendix G

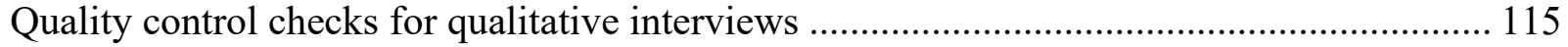

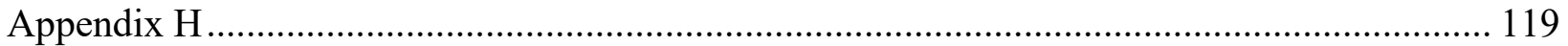

Audit trail for the interview process............................................................................. 119

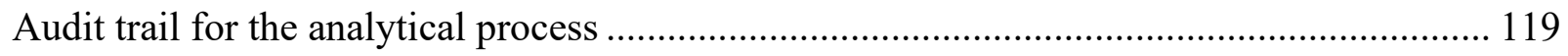




\section{List of Tables}

Table 1. Frequency in which themes were endorsed by each participant group.........................38 


\section{List of Figures}

Figure 1. SSPS COAST Logic Model ................................................................................25

Figure 2. COAST activities and corresponding goals.......................................................28

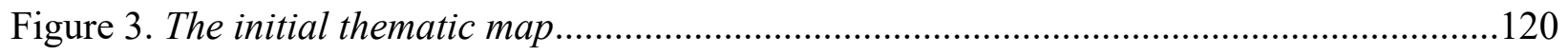

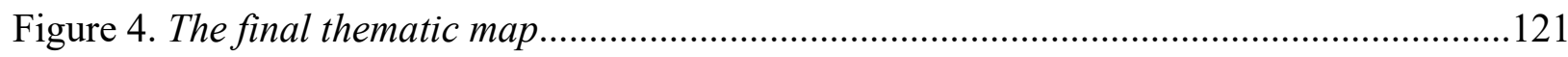




\section{A qualitative evaluation of a co-responding mobile crisis intervention team in a small}

\section{Canadian police service}

\section{Introduction}

In a recent review of 85 unique studies of contact between police and individuals with mental illness, it was estimated that one in four people with a mental illness have a history of police arrests, one in ten individuals encounter police in their pathway to mental health care, and one in one hundred police dispatches and encounters involve a person with a mental illness (Livingston, 2016). Research has also shown that police officers provide close to one-third of all emergency health referrals for those experiencing severe crises (Borum et al., 1998; Deane et al., 1999). Increasingly then, we are seeing police officers act as frontline responders in mental health emergencies and crises. This poses several challenges for the policing community as police officers often lack the knowledge and skills to handle these encounters in an appropriate and effective manner (Landeen et al., 2004; Morabito et al., 2012). This can lead to unfavourable outcomes, not only from a policing perspective, but also for the individuals experiencing crises.

For example, crisis encounters can require a significant amount of police resources (e.g., emergency department wait times), which takes resources away from other, more traditional law enforcement activities (e.g., patrol; Livingston, 2016; Shapiro et al., 2015). From the client perspective, because the police (and the community social services sector) are often ill-prepared to respond appropriately to the challenges being encountered, this can lead to the unnecessary criminalization of persons experiencing mental health related crises who are otherwise harmless (Morabito et al., 2012; Shapiro et al., 2015). Indeed, as discussed in more detail below, the police in North America are often forced to respond to crisis calls by jailing individuals, either because the police are not aware of available resources in the community (Borum et al., 1998; Lamb et 
al., 2002; Lord et al., 2011) or because access to those resources is barred (e.g., community resources may be over-committed; Shapiro et al., 2015; Wood et al., 2011).

As mentioned, many police officers lack the knowledge and skills to not only handle mental health calls in an effective manner, but also to identify that a call is mental health related in the first place (Morabito et al., 2012). However, the challenges associated with responding to crisis calls has not gone unnoticed in the policing community. In fact, there have been several steps taken to better educate and prepare police officers (and recruits) on how to appropriately manage situations in which individuals are experiencing crises. For example, Canada's national police force, the Royal Canadian Mounted Police (RCMP), has implemented mandatory crisis intervention and de-escalation training for all its officers to improve the way in which the police approach these types of situations (RCMP, 2018). Furthermore, the Atlantic Police Academy, located in Prince Edward Island, is just one among many Canadian police academies that have mandated mental health training in the curriculum for prospective officers, recognizing the need for recruits to be more adequately prepared for encounters with people in crisis when they become frontline officers (Canadian Centre of Public Safety Excellence, n.d.; Cotton \& Coleman, 2008). Municipal police agencies across the country are also requiring that their officers receive training on mental health issues (e.g., several police services in British Columbia; Hall \& Weaver, 2008).

Along with better training, the perpetuating relationship between police officers and individuals experiencing mental health crises has led to the creation and implementation of various specialized response programs within police services across North America (Coleman \& Cotton, 2010; Cross et al., 2014; Steadman et al., 2000). These programs are often designed to divert individuals experiencing crises from the criminal justice system (CJS) and steer them 
towards relevant community resources and services for the treatment of mental illnesses

(Compton et al., 2014; Lord et al., 2011; Ritter et al., 2010). In addition to providing better and more appropriate care for clients, these diversion programs are intended to reduce pressure on both the CJS (e.g., by decreasing officer time spent on crisis calls), and the health care system (e.g., by lessening the number of visits to emergency departments through appropriate on-scene intervention; Shapiro et al., 2015). These specialized programs also aim to provide better tools to officers to allow them to effectively de-escalate crises, prevent injuries to both clients and police officers, and reduce the number of arrests of individuals experiencing mental health related challenges (Cross et al., 2014; Shapiro et al., 2015).

Despite the promising outlook of crisis intervention strategies, evaluations of these specialized response programs are scarce and often limited in scope (Fisher et al., 1990; Landeen et al., 2004). A lack of program evaluation can be problematic as it does not allow for an evidence-based approach in determining program fidelity (i.e., whether the program is being delivered in the way that it was intended to be delivered and whether the goals of the program are actually being met). Evaluations of these programs may also be useful in determining service gaps that may ultimately influence best practices for service delivery. For example, Landeen and colleagues (2004) conducted a study in which they identified specific cohorts of individuals served by a Crisis Outreach and Support Team (COAST) in order to identify best practices based on these groupings of service users. They identified one cohort as "Symptoms Disturbing Others - Suicide" in which police, family members, neighbours, or agencies refer an individual to COAST with threats, plans, or actions specific to self-harm or suicidal behaviours. By identifying this specific type of service user, it reflects a need to incorporate suicide prevention techniques into the COAST training, ultimately informing best practices (Landeen et al., 2004). 
Similar to Landeen and colleagues' (2004) study, the present study will aim to evaluate the efficacy of a co-responding police-mental health program provided by the South Simcoe Police Service (SSPS) in Bradford, Ontario. The program is delivered by SSPS in partnership with the Canadian Mental Health Association (CMHA; Barrie location) and the York Support Services Network (YSSN). This program was modeled after the COAST program developed in Hamilton, Ontario. The evaluation will build off an existing quantitative evaluation of the program (Semple et al., 2020) and include a qualitative assessment of the program (in terms of benefits and challenges) through interviews with the COAST staff, senior leadership in the SSPS, CMHA, and YSSN, and SSPS frontline officers. The goal of the evaluation is to inform best practices for service delivery.

\section{Literature Review}

The following literature review will first provide an overview of reasons why persons with a mental illness come into contact with the police, often rendering police officers as first responders when individuals are experiencing a crisis. Second, various factors will be discussed in relation to police responses to people in crisis, including how service users are perceived, as well as challenges and outcomes associated with limited mental health services. Next, two models of specialized response programs will be discussed, including outcomes from previous research that has examined these specific programs. Lastly, the current program under evaluation, the SSPS COAST, will be presented along with a review of outcomes from the initial quantitative assessment of the initiative.

\section{Mental Illness and the Criminal Justice System}

Increased police involvement with individuals experiencing mental health crises can be attributed to a number of factors. A key reason why these encounters have increased relates to 
revisions in the delivery of services for those living with a mental illness. For example, deinstitutionalization, which began in the late 1900s, shifted the reliance on mental institutions as the primary caregiver of persons with mental illnesses (PMIs) towards an integrated approach with roles played by general hospitals and community-based outpatient services (Sealy \& Whitehead, 2004). This movement resulted in more PMIs living in the community, as opposed to being confined within psychiatric hospitals (Borum et al., 1998; Ruiz \& Miller, 2004).

Complicating matters further, while psychiatric institutions continued to close (or at least reduce their number of beds), government expenditures for mental health programs in the community also gradually reduced (Cooper et al., 2004) and criteria for involuntary commitment became more stringent, making it harder to admit non-compliant individuals to a hospital (Finn \& Sullivan 1989; Stefan, 1996). The end result of all these changes has been a greater number of PMIs living in communities, challenges in relation to PMIs accessing adequate treatment in the community, and greater contact with police officers when PMIs are unable to adequately cope with their symptoms (Cooper et al., 2004).

Compounding the deinstitutionalization challenges is the nature of mental illnesses, especially issues related to co-morbidity. Although not typical of all PMIs, some PMIs experience substance abuse problems on top of their mental health issues. In fact, individuals diagnosed with a severe mental illness are three times more likely to have a substance abuse problem when compared to the general population (Abram, 1990; Sharma \& Bennett, 2015). It is often these substance abuse problems that bring PMIs into contact with the law. For example, in a sample of 331 individuals with a severe mental illness, it was reported that $20 \%$ had been arrested or picked up by the police prior to hospitalization, most commonly for substance related offences (Borum et al., 1997). 
Relatedly, research suggests that substance abuse may be an important factor linking violent behaviour to mental illness (Swartz et al., 1998a). Often individuals with severe mental illness who cannot access adequate treatment resort to other coping mechanisms to deal with their symptoms, such as alcohol and/or other illicit substances (Abram, 1990; Sharma \& Bennett, 2015). Swartz and colleagues (1998b) provided several mechanisms linking mental illness, substance abuse, and violence including the disinhibition of aggressive behaviours because of substances, substance-induced exacerbation of agitation and psychotic symptoms, and exacerbation of interpersonal conflicts due to substance abuse. Whatever the underlying mechanism, in cases where mental illness is associated with violence, PMIs are more likely to come into contact with the police.

Police responses to people in crisis. There are many factors that contribute to the mishandling of persons suffering from mental health related issues by law enforcement officers. Although police officers are commonly the first responders to people in crisis, they typically report that these types of calls pose several challenges (Lord et al., 2011). For example, police officers often report that they do not feel adequately trained and prepared to respond to these types of situations (Borum et al., 1998; Reuland et al., 2009) as PMIs are often perceived by the police as unpredictable, leading to a heightened assessment of risk (Lord et al., 2011; Morabito et al., 2012). The perceived unpredictability and heightened sense of risk associated with PMIs can sometimes stem from a display of odd behaviour and non-compliance. Police officers may be unaware of the presence of a mental illness and may not attribute odd behaviour and noncompliance to mental health related issues, further escalating the encounter (Morabito et al., 2012). Consistent with this, Cordner (2006) noted that police encounters in which there is noncompliance are more likely to escalate into a dangerous and sometimes violent encounter. Of 
course, a PMI may fear being handled by an unfamiliar police officer and being removed from their home to an unknown place, increasing stress levels in an already high stress situation (Ruiz \& Miller, 2004); this too can increase the chance of encounters becoming violent. Furthermore, as Ruiz and Miller (2004) highlight, calls for service involving PMIs are typically dispatched as "a disturbance of the peace", which can often be perceived by the police as the most dangerous type of call, leading police officers to approach PMIs in a hostile manner. For these reasons, police officers can be left feeling ill-prepared for encounters with PMIs and frustrated in their attempts to adequately handle these types of situations.

Further contributing to the policing challenges associated with PMIs, these interactions are often described as being very time-consuming as they utilize a substantial amount of police resources, typically related to emergency department wait times (Morabito at al., 2012; Thompson, 2010). When an individual is apprehended under the Mental Health Act (MHA), police officers are typically required to wait in the emergency department until the PMI is seen by a physician. This can mean that police officers are spending hours in the emergency department, preventing them from engaging in their regular operational duties (Provincial Human Services and Justice Coordinating Committee [PHSJCC], 2011; Reuland et al., 2009). For example, officers with the Vancouver Police Department wait an average of 1 hour and 11 minutes on calls related to a PMI and can wait up to five hours in some instances (Thompson, 2010). In another Canadian study, researchers found police officers waited an average of four hours in the emergency department on calls related to PMIs (Pizzingrilli et al., 2015). Because of these extensive wait times, some hospitals in Ontario have initiated inter-agency agreements with local police services in attempts to reduce wait-times associated with apprehended PMIs (PHSJCC, 2011). 
Furthermore, police officers are often unfamiliar with the available resources within their communities to assist PMIs, often leaving much to the discretion of individual police officers in terms of how to handle crisis calls (Lord et al., 2011; Ritter et al., 2010). Even when officers are familiar with their community's resources, resources are not always available. For example, often small communities have limited mental health services and psychiatric inpatient beds, and officers may be more inclined to jail the individual if no resources are available (Lamb et al., 2002). In addition, because the criteria for involuntary admission to a hospital facility has become more stringent (Finn \& Sullivan 1989), and because police officers have an obligation to maintain public safety in instances where a PMI may be displaying violent or dangerous behaviour, PMIs may be more likely to be arrested than others (Lamb et al., 2002; Wolff, 1998). In part because of these sorts of issues, Wood and colleagues (2011) noted that some police officers will arrest and charge a PMI with a minor offence in hopes of accessing better treatment through the CJS. However, this approach to dealing with mental illness can be problematic because typically these PMIs will not receive adequate treatment as jails are often ill-equipped to intervene in mental health related issues (Akland \& Akland, 2008). Overall, there is clearly a need for improvement in managing interactions between PMIs and the police.

\section{Specialized Response Programs}

The need to improve police services to individuals experiencing crises has led to the implementation of several specialized response programs across North America. It is estimated that there are now over 2,700 of these programs implemented in the United States (US) alone, many of which differ in service modality (Compton et al., 2014). Although there are now numerous configurations of these specialized response programs, they generally follow a few specific models (Shapiro et al., 2015). The Crisis Intervention Team (CIT) and the Mobile Crisis 
Intervention Team (MCIT) are two of the most popular models of specialized response programs. Each of these programs will be described below, and the limited evaluation research associated with the programs will be briefly reviewed. Before that is done, however, several challenges associated with evaluating these programs will be briefly discussed.

First, developing general outcome measures associated with these programs can be difficult because of the diversity in clients and situations involved in these programs (Landeen at al., 2004). For example, there are no age or diagnostic criteria for service and clients are likely to have varying needs, so it can be challenging to identify appropriate outcomes for the population as a whole. Landeen and colleagues (2004) suggested that categorizing service users into specific cohorts (e.g., Symptoms Disturbing Self, Information Seeking) may be useful in identifying service gaps and developing best practices relative to individual service user needs when evaluating program outcomes. Second, data collection on client satisfaction can be challenging due to low response rates and difficulty tracking service users (Landeen et al., 2004). This issue is particularly important because the perception of program benefits and challenges from the perspective of the client is invaluable when it comes to assessing program fidelity and effectiveness. Third, police officers must volunteer to participate in specialized training which may affect the ability to find significant results with respect to program evaluation outcomes. For example, it could be that officers who volunteer for crisis intervention training may already possess quality de-escalation skills and see the importance of diverting individuals with a mental illness from the CJS (Taheri, 2016). Finally, many specialized response program evaluations focus on improved knowledge and skills in understanding and responding to PMIs among police officers (i.e., officer-level outcomes), rather than focusing on the actual outcomes associated with increased knowledge and skills (i.e., patient-level outcomes; e.g., decreased use of force 
encounters, increased diversion from the CJS, additional referrals to mental health services; Compton et al., 2008; Morabito et al., 2012). All this considered, quality evaluations of these specialized response programs are often hard to find.

Crisis Intervention Team (CIT). The most popular model for improving police interactions with PMIs is known as the Crisis Intervention Team (CIT) approach. This model, also known as the Memphis Model, was developed in response to a shooting incident in Memphis in1988. The incident involved an individual experiencing a mental health crisis who came into contact with the police (Cross et al., 2014). Although many CIT programs that exist today deviate from the original model, the overarching principles generally remain fairly consistent with the original CIT model (Cross et al., 2014).

The primary goals of the CIT approach are to reduce both officer and client injuries during crisis intervention encounters and to divert individuals in crisis from the CJS. Police officers who volunteer for the training receive approximately 40 hours of instruction, largely provided by mental health professionals. The training is aimed at improving officers' knowledge of mental illnesses, their signs and symptoms, and the ability to recognize when someone is experiencing a crisis; mental illness treatment; as well as de-escalation techniques. These programs are also intended to increase officers' confidence in their ability to respond effectively to persons in crisis and improve officer attitudes towards the mentally ill (Cross et al., 2014). Shapiro and colleagues (2015) also suggest that trained officers should become more knowledgeable of their own community's mental health services and resources.

Research on the effects of CIT programs are limited, often focusing on the process as opposed to outcomes (Morabito et al., 2012). In Compton and colleagues (2008) comprehensive review of CIT programs they noted positive effects on officers' attitudes, beliefs, and knowledge 
associated with the CIT training component. For example, when compared to non-CIT trained officers, CIT officers were less likely to stigmatize individuals with schizophrenia and were less likely to associate mental illness with personal attributes (e.g., bad character). In addition, CIT training among police officers seems to improve the ability to identify individuals with a mental illness and respond appropriately, as well as increase knowledge of resources and services available in the community. Compton and colleagues (2008) also noted that CIT trained officers generally felt more prepared in dealing with PMIs and they were more confident in the mental health systems ability to assist. In addition, lower arrest rates of PMIs and lower costs associated with the CJS were also highlighted in this review, primarily attributed to the fact that diversion resulting from CIT is at the pre-booking stage (i.e., an individual is diverted from the CJS prior to being arrested and charged with an offence; Compton et al., 2008). These types of results are generally consistent with other evaluations of CIT programs (Cross et al., 2014; Hanafi et al., 2008; Ritter et al., 2010; Watson \& Fulambarker, 2012).

Despite the generally positive reviews highlighted in most evaluations of CIT programs, there are other reviews that are less encouraging. For example, Taheri (2016) conducted a systematic review and meta-analysis of actual CIT outcomes. More specifically, she examined whether CIT programs have a positive effect on arrest rates of PMIs, use of force, and officer safety/injury, although officer safety/injury could not be assessed due to limited data. For both arrest rates and use of force, Taheri found null effects. When comparing CIT trained officers to non-CIT trained officers, it was found that CIT trained officers were less likely to arrest PMIs, however this difference was not statistically significant $(\mathrm{ES}=.18,95 \%$ confidence interval [CI] $=[-.136, .496])$. Similarly, it was found that CIT training had no significant positive effect on use of force encounters with PMIs $(\mathrm{ES}=-.30,95 \% \mathrm{CI}=[-.759, .149])$. These results highlight some 
of the issues with respect to program evaluation that were discussed previously, such as the voluntary nature of these programs, as well as the limited number of evaluations that currently exist. This does not suggest that CIT programs do not result in positive outcomes for PMIs and police officers; however, it may suggest that further improvements are needed with respect to CIT programs (Taheri, 2016).

Mobile Crisis Intervention Team (MCIT). A second specialized crisis response model that has been gaining attention is the co-responding police-mental health approach, which involves a collaborative effort between police officers and mental health professionals (Kirst et al., 2015; Lamanna et al., 2018; Shapiro et al., 2015). This model is also referred to as the MCIT and it is the predominant model in Canada (Lamanna et al., 2018; Shapiro et al., 2015).

The goals of the MCIT approach include, but are not limited to, de-escalating crises, preventing client and officer injury, increasing referrals to mental health services in the community, and alleviating pressure on both the CJS and the health care system (Borum, 2000; Shapiro et al., 2015). In Canada, these programs have gone by several different names, such as the Crisis Outreach and Support Team (COAST) in Hamilton (Ontario), the Integrated Mobile Crisis Response Team (IMCRT) in Victoria (British Columbia), and the Mental Health Mobile Crisis Team (MHMCT) in Halifax (Nova Scotia; Shapiro et al., 2015). Regardless of their name, the approach is consistent with the idea that a collaborative response between the justice system and the health care system will improve the ways in which services are provided to those experiencing crises.

Kisely and colleagues (2010) completed one of the few evaluations of a MCIT in Canada. They conducted a controlled before-and-after evaluation of the MHMCT in Nova Scotia to examine the impact of the collaborative effort between mental health and police services. Over a 
three-year period, they found that the number of crisis calls in which the MHMCT responded to nearly tripled, with over $80 \%$ of clients being new to the service, identifying a great need for this program. Despite an increase in service use, time spent on scene by non-MHMCT police officers and call-to-door times for the MHMCT were both reduced, showing positive outcomes for the program and the police service as a whole. Focus groups including service users, family and friends of service users, MHMCT staff, and police officers supported the quantitative findings and showed increased availability and accessibility to the program. Despite police officers and MHMCT staff agreeing that both parties seemed to work well together, non-MHMCT officers expressed a lack of availability of MHMCT staff to respond to crisis calls, which may reflect a need for additional funding for MHMCT members.

More recently, Lamanna and colleagues (2018) conducted a mixed-method study in Toronto, Ontario, where they compared several outcomes between a co-responding policemental health team (involving a specially trained officer and a mental health nurse who are secondary responders when needed) and a police-only team. The outcomes included injury and arrest rates, response times, and service user's perceptions of the two approaches. Data analysis of administrative data showed that the MCIT had low rates of service user injuries and arrests (no comparisons were made to the police-only team). Response times for MCIT were longer than police-only teams, but when compared to other MCIT program evaluations they were faster to respond (Baess, 2005). The MCIT had higher rates of escorts to the hospital including voluntary escorts, and lower handover times to emergency services when compared to the police-only team. The MCIT also had overall lower rates of involuntary escorts to emergency services.

A qualitative analysis of the Toronto program showed that service users were consistently satisfied with the MCIT approach; for example, they valued the responders' knowledge of 
mental health challenges and de-escalation skills, as well as their compassionate and noncriminalizing approach (Lamanna et al., 2018). When commenting on the police-only team, some service users recalled feelings of being criminalized when handcuffs were deployed and large numbers of police officers and marked vehicles appeared; all of these factors contributed to a more negative experience for the service user. Lamanna and colleagues (2018) attributed these negative experiences to differences in officer training, culture, and skills in dealing with people in crisis, as well as a lack of mental health expertise among the police-only team. In line with past research, it was also suggested police officers commonly perceive PMIs as unpredictable, resulting in feelings of dangerousness, which may provoke officers to use more forceful tactics (Lord et al., 2011; Morabito et al., 2012; Ruiz \& Miller, 2004).

Lastly, Shapiro and colleagues (2015) conducted a recent review of global co-responding police-mental health programs and their outcomes. They noted that comparative evaluations of these programs can often be challenging as they can vary in terms of populations served, funding levels, program procedures, hours of operations, expertise, and training (Kean et al., 2012; Ligon, 1997; Shapiro et al., 2015). In addition, these programs can also vary in the methods chosen for improved outcomes such as partnership building between the criminal justice and health systems, referrals, consumer follow-ups, and program presence in vulnerable areas (Patterson, 2010). Despite these challenges, Shapiro and colleagues (2015) found some evidence that co-responding models reduce arrests and time spent on calls, subsequently alleviating some of the pressure on the CJS. In addition, program perception was generally positive among service users and their families. Mixed evidence was found with respect to the use of de-escalation, injuries, officer perception of PMIs, cost-effectiveness, and hospital admissions (Shapiro et al., 2015). 


\section{South Simcoe Police Service's COAST Program}

Although the results of Shapiro and colleagues (2015) review of co-responding policemental health programs were conflicting, it revealed a need for program maintenance and subsequent evaluations. The continued evaluation of any particular program is imperative for program fidelity with respect to informing best practices and improving program implementation. Long-term tracking of policing programs is relatively rare (Huey et al., 2017; Sherman, 2013) and we hope to ensure that this is not the case with South Simcoe's program. The current study aims to provide a qualitative evaluation of the SSPS COAST program that builds on an initial quantitative assessment of the program that was conducted by Semple and colleagues (2020).

South Simcoe Police Services' community-based COAST is an MCIT program in which a plain-clothed officer and one of two crisis professionals work in cooperation to manage crisis calls. As mentioned previously, this program was implemented in partnership with the Barrie branch of the Canadian Mental Health Association (CMHA) and the York Support Services Network (YSSN). The South Simcoe Police Service consists of 86 full-time police officers servicing approximately 486 square kilometres of land and a population of 74,320 residents (SSPS, 2017). The jurisdiction is split into two districts, one of which is mostly rural land. In

general, regular patrol officers will serve one district while the COAST is responsible for servicing the entire jurisdiction.

The officer involved in the COAST is specially trained in mental health services and has completed a number of relevant courses including Mental Health First Aid, Suicide Intervention, Critical Incident Stress Management, and Crisis Intervention. Both of the mental health 
professionals (i.e., crisis response workers or CRWs) are also professionally trained to assist and manage individuals experiencing mental health related challenges and crises.

The hours of COAST operation in South Simcoe were initially Tuesday to Friday from 10am to 8pm. The CRW's worked on Wednesdays, Thursdays, and Fridays, meaning the COAST officer responded to calls alone one day a week. In 2019, the hours of operation increased to five days per week, Monday to Friday, from 10am to 8pm. YSSN provides a CRW three full-time days per week and CMHA provides a CRW 2 full-time days per week. The COAST officer works 4 full-time days per week. An alternate COAST officer covers for the COAST officer on the fifth day of operation. The alternate COAST officers have been provided with some additional training in mental health.

All COAST members work in plain clothes and operate out of an unmarked police vehicle. When a crisis call comes in, a general patrol officer assesses the situation to determine threat level and safety concerns. Once the situation is deemed a non-threat to officer and public safety, the call will ideally be handed over to COAST. This protocol reflects one of the goals of COAST, which is to assist general patrol officers who do not have extensive training in how to appropriately manage individuals in crisis. When COAST is unable to attend a live crisis call, general patrol officers will typically flag the call for COAST to review. COAST will then determine whether the call requires a follow-up with the service user.

SSPS COAST Logic Model. In terms of the underlying theory of the SSPS COAST program, there is very limited documentation available in regard to program assumptions, inputs, activities, outcomes, and so on, and no existing logic model exists for the program. Utilizing the limited information available, I created a SSPS COAST Logic Model (see Figure 1) to solidify the underlying assumptions of the program, as supported by the literature, and to outline the 
situation, program inputs, activities, audience, outputs, and outcomes. The creation of the logic model was intended to address the following questions: (1) What is the program?; (2) How/why is the program supposed to work?; and (3) What are the goals of the program? The logic model also allows for accountability in terms of program tracking and maintenance (i.e., is the program operating as intended). The logic model was reviewed and approved by the SSPS COAST Officer and the SSPS Chief of Police. We discuss elements of the logic model below Figure 1. 


\section{Figure 1}

\section{SSPS COAST Logic Model}

\begin{tabular}{|c|c|c|c|c|c|}
\hline Situation & Inputs & Activities & Audience & Outputs & Outcomes \\
\hline $\begin{array}{l}\text { - Deinstitutionalization } \\
\text { and lack of community } \\
\text { resources led to police } \\
\text { officers being first } \\
\text { responders for } \\
\text { individuals } \\
\text { experiencing mental } \\
\text { health emergencies and } \\
\text { crises } \\
\text { - Most police officers } \\
\text { lack knowledge, skills, } \\
\text { training, etc., to } \\
\text { appropriately handle } \\
\text { individuals in crisis, } \\
\text { leading to } \\
\text { criminalization and/or } \\
\text { apprehensions } \\
\text { - Crisis calls consume a } \\
\text { significant amount of } \\
\text { police resources (e.g., } \\
\text { emergency department } \\
\text { wait times) } \\
\text { framework with YSSN } \\
\text { and CMHA Barrie } \\
\text { - Incarceration and } \\
\text { apprehension do not } \\
\text { address root causes of } \\
\text { problems, which may } \\
\text { lead to higher } \\
\text { recurrence rates } \\
\text { - Unfavourable } \\
\text { outcomes for both SSPS } \\
\text { users exhaustees) and service } \\
\text { incarceration) } \\
\text { fial collaborative } \\
\text { - }\end{array}$ & 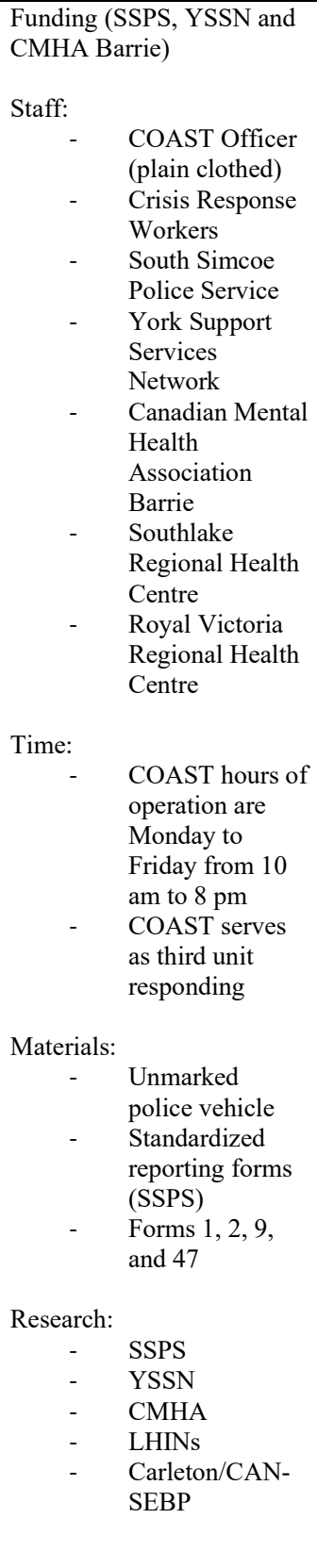 & $\begin{array}{l}\text { - Monitor all } \\
\text { incoming crisis } \\
\text { calls } \\
\text { - De-escalation } \\
\text { of crisis calls } \\
\text { - Diversion from } \\
\text { criminal justice } \\
\text { system (CJS) } \\
\text { and/or } \\
\text { emergency } \\
\text { department (ED) } \\
\text { - Conduct } \\
\text { routine follow- } \\
\text { ups } \\
\text { - Connect } \\
\text { service users to } \\
\text { appropriate } \\
\text { community } \\
\text { resources } \\
\text { - Community } \\
\text { engagement } \\
\text { events } \\
\text { - Program } \\
\text { evaluation and } \\
\text { monitoring } \\
\text { - Conduct } \\
\text { information } \\
\text { sessions with } \\
\text { officers }\end{array}$ & $\begin{array}{l}\text { - Service users } \\
\text { - South Simcoe } \\
\text { Police Service } \\
\text { - Criminal } \\
\text { justice system } \\
\text { - Healthcare } \\
\text { system } \\
\text { (Southlake } \\
\text { Regional Health } \\
\text { Centre and } \\
\text { Royal Victoria } \\
\text { Regional Health } \\
\text { Centre) } \\
\text { - South Simcoe } \\
\text { community }\end{array}$ & $\begin{array}{l}\text { - } 865 \text { total crisis } \\
\text { calls; } 275 \text { live calls } \\
\text { - } 7 \% \text { hospital } \\
\text { outcomes for } \\
\text { COAST; } 52 \% \\
\text { hospital outcomes } \\
\text { for general patrol } \\
\text { - 23-minute } \\
\text { decrease for total } \\
\text { time spent on call } \\
\text { (both COAST and } \\
\text { general patrol) } \\
\text { - } 40 \text {-minute } \\
\text { decrease for total } \\
\text { time spent on call } \\
\text { when COAST } \\
\text { responds } \\
\text { (compared to } \\
\text { general patrol) } \\
\text { - Average time } \\
\text { spent in ED when } \\
\text { COAST responds } \\
\text { is } 59 \text { minutes; } 103 \\
\text { minutes for general } \\
\text { patrol ( } 44 \% \\
\text { decrease in time) } \\
\text { - Approximately } 16 \\
\text { engagement events } \\
\text { completed } \\
\text { apprehensions for } \\
\text { - } 81 \text { ED diversions } \\
\text { (approximately } 4+ \\
\text { per month) } \\
\text { - } 32 \text { ( } 42.1 \% \text { ) } \\
\text { resource referrals } \\
\text { for COAST and } 58 \\
\text { (29.7\%) for general } \\
\text { patrol } \\
\end{array}$ & 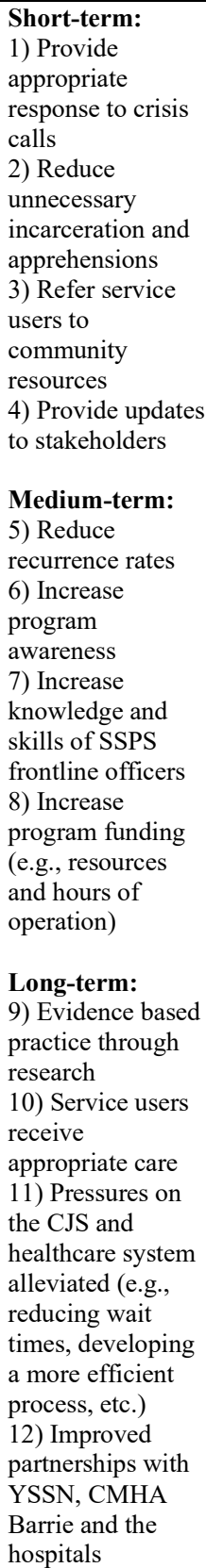 \\
\hline
\end{tabular}

Note: Statistics for “Outputs” as of February 2019. 


\section{Figure 1 (cont'd)}

\begin{tabular}{|c|c|}
\hline Assumptions & External Factors \\
\hline $\begin{array}{l}\text { 1) Police officers remain first responders for individuals experiencing mental health related emergencies and } \\
\text { crises, maintaining the need for such programs (Borum, Deane, Steadman, \& Morrisey, 1998; Livingston, 2016; } \\
\text { Landeen, Pawlick, Rolfe, Cottee, \& Holmes, 2004; Morabito, Kerr, Watson, Draine, Ottati, \& Angell, 2012; } \\
\text { Shapiro, Cusi, Kirst, O-Campo, Nakhost, \& Stergiopoulos, 2015; Outcomes 1-12). } \\
\text { 2) Co-responding approach involving police and mental health professionals will lead to desired results (Shapiro } \\
\text { et al., 2015, Lamanna, Shapiro, Kirst, Matheson, Nakhost, \& Stergiopoulos, 2018; Kisely, Campbell, Peddle, } \\
\text { Hare, Pyche, Spicer, \& Moore, 2010; Outcomes } 1,2,3,5,10 \text { and 12). } \\
\text { 3) Plain clothed officer and unmarked police vehicle will assist with de-escalation (Perkins, Cordner, \& } \\
\text { Scarborough, 1999; Lamanna et al., 2018; Outcomes 1, 2, 5, and 10). } \\
\text { 4) Program activities will effectively de-escalate crisis situations and divert individuals from the criminal justice } \\
\text { system (Outcomes 1, 2, 3, 7, 9, and 11). } \\
\text { 5) Program activities will reduce unnecessary apprehensions and alleviate pressure on the local hospital centres } \\
\text { (Outcome } 2 \text { and 11). } \\
\text { 6) Routine follow-ups and resource referrals will reduce recurrence rates (Outcomes 5, 10, 11). } \\
\text { 7) Implementation of COAST will increase knowledge and skills among general patrol which will result in } \\
\text { appropriate crisis response when COAST is not available (Semple et al., 2018; Hanafi, Bahora, Demir, \& } \\
\text { Compton, 2008; Compton, Bakeman, Broussard, Hankerson-Dyson, Husbands, Krishan, Stewart-Hutto, D’Orio, } \\
\text { Oliva, Thompson, \& Watson, 2014; Outcomes } 1,2,3 \text {, and 7). } \\
\text { 8) Providing referrals to community resources will result in service users receiving appropriate care (Outcomes } 2 \text {, } \\
\text { 3, 5, and 10). } \\
\text { 9) Community resources available will be sufficient and accessible for services users in need (Outcomes 5, 10 } \\
\text { and 11). } \\
\text { 10) Community engagement events will increase program awareness and maintain communication between } \\
\text { various stakeholders (Outcomes } 4,6,8 \text {, and } 11 \text { ). } \\
\text { 12) Program evaluation and monitoring will result in best practices (since the initial evaluation was completed by } \\
\text { Semple and colleagues (2018), SSPS COAST has gained two additional crisis response workers; Outcomes } 1,8 \text {, } \\
\text { 9, and 12). }\end{array}$ & $\begin{array}{l}\text { - Number of available } \\
\text { resources in the } \\
\text { community (e.g., crisis } \\
\text { beds) } \\
\text { - Affordability of long- } \\
\text { term care for service } \\
\text { users } \\
\text { - Unexpected changes in } \\
\text { program resources and } \\
\text { funding } \\
\text { - Influence of social } \\
\text { environment and } \\
\text { political climate (e.g., } \\
\text { "tough on crime" } \\
\text { approach) } \\
\text { - Service users utilizing } \\
\text { community resources }\end{array}$ \\
\hline
\end{tabular}

First, the logic model outlines the situational context that led to the creation of the

program. This includes factors such as deinstitutionalization and the fact that police officers

often lack the skills and knowledge to appropriately handle individuals in crisis. The model then

presents the program inputs (i.e., the resources invested into the program). These inputs include

factors such as funding, staffing, hours of operation, materials, and research. The activities that

are carried out as part of the COAST program include monitoring all incoming crisis calls, de-

escalating crisis calls, diverting service users from the CJS and/or the emergency department

(ED), conducting routine follow-ups, connecting service users to the appropriate community

resources, participating in community engagement events, on-going monitoring and evaluating

of the COAST, and conducting information sessions with SSPS frontline officers. The activities

of the COAST were established to allow the program to attain the intended outcomes. For 
example, community engagement events are aimed to increase program awareness while program monitoring and evaluations will encourage evidence-based practice.

The audience portion of the logic model indicates whom the program is targeting, including both the primary and secondary audiences. For this particular program model, the primary audience (i.e., the main population that is being targeted) is the service user (i.e., people in crisis), while the secondary audiences (i.e., groups who are impacted by the program, but are not the direct recipients of the program) include SSPS, the CJS, the healthcare system, and the community more generally. The outputs include the products of the program activities that are often viewed as the quantification of activities. Some of the outputs that are included in the model are the number of crisis calls, the percentage of hospital admissions for apprehensions, time spent on call, the number of ED diversions, and so on. Finally, the outcomes provide an overview of the changes expected to result from the program. These range from short-term to long-term outcomes. For example, a short-term goal of the COAST is to reduce unnecessary apprehensions, a medium-term goal is to increase the knowledge and skills of SSPS frontline officers, and a long-term goal is to improve the partnerships with YSSN, CMHA, and the local hospitals.

The assumptions described above outline the underlying theories and/or beliefs about the program and its context, which can influence the development and activities of the program. The assumptions and outcomes of the program are consistent with the literature in relation to these types of specialized response programs. Each of the assumptions is mapped on to the relative outcomes. In addition, the activities of the COAST are directly related to the intended outcomes of the program (see Figure 2). For example, the use of a plain-clothed officer and unmarked vehicle will contribute to the de-escalation of crisis calls, ultimately providing a more 
appropriate response and reducing unnecessary incarceration and apprehensions (Perkins et al.,

1999; Lamanna et al., 2018).

\section{Figure 2}

COAST activities and corresponding goals

\begin{tabular}{|c|c|}
\hline COAST Activities & Corresponding Goal(s) \\
\hline De-escalation of crisis calls & $\begin{array}{l}\text { - Provide appropriate response to crisis } \\
\text { calls } \\
\text { - Reduce unnecessary incarceration and } \\
\text { apprehensions }\end{array}$ \\
\hline $\begin{array}{l}\text { Diversion from criminal justice system (CJS) } \\
\text { and/or emergency department (ED) }\end{array}$ & $\begin{array}{l}\text { - } \quad \text { Reduce unnecessary incarceration and } \\
\text { apprehensions } \\
\text { - Pressures on the CJS and healthcare } \\
\text { system alleviated (e.g., reducing wait } \\
\text { times, developing a more efficient } \\
\text { process, etc.) } \\
\text { - Provide appropriate response to crisis } \\
\text { calls }\end{array}$ \\
\hline Conduct routine follow-ups & $\begin{array}{l}\text { - } \text { Service users receive appropriate care } \\
\text { - } \quad \text { Refer service users to community } \\
\text { resources }\end{array}$ \\
\hline $\begin{array}{l}\text { Connect service users to appropriate } \\
\text { community resources }\end{array}$ & $\begin{array}{ll}\text { - } & \text { Refer service users to community } \\
& \text { resources } \\
\text { - } & \text { Reduce recurrence rates } \\
\text { - } & \text { Service users receive appropriate care }\end{array}$ \\
\hline Community engagement events & $\begin{array}{l}\text { - } \quad \text { Provide updates to stakeholders } \\
\text { - } \quad \text { Increase program awareness }\end{array}$ \\
\hline Program evaluation and monitoring & $\begin{array}{l}\text { - } \quad \text { Evidence based practice through research } \\
\text { - Increase program funding (e.g., resources } \\
\text { and hours of operation) }\end{array}$ \\
\hline $\begin{array}{l}\text { Conduct information sessions with SSPS } \\
\text { frontline officers }\end{array}$ & $\begin{array}{l}\text { - Increase knowledge and skills of SSPS } \\
\text { frontline officers }\end{array}$ \\
\hline
\end{tabular}

Note: Other activity(ies): Monitor all incoming crisis calls; Other goal(s): Improve partnerships with YSSN, CMHA, and hospitals

Lastly, the external factors listed above are factors that impact the program but are beyond the control of program planners and overseers (e.g., available mental health beds in the community). These factors are likely to influence program success. 
The Initial Quantitative Evaluation. Semple and colleagues (2020) provided an initial quantitative assessment of South Simcoe's COAST program over a 12-month period from May 1, 2017 to April 30, 2018. The COAST was implemented at the midpoint of the 12-month period. Historical data were collected by SSPS using standardized reporting forms from May 1, 2017 to October 31, 2017. These data were compared to data collected from November 1, 2017 to April 30, 2018 while the COAST was operating. The variables that were examined included: (1) the nature of calls (e.g., mentally ill, suicide-related, assist medical, well-being check, or a person in crisis [PIC]), (2) call disposition (i.e., the outcome of the call, e.g., resources provided, voluntary admission to a hospital, apprehension), (3) time spent on in-progress calls, (4) total time spent in the ED, and (5) cost savings. The analysis included a comparison of general patrol before and after COAST implementation, and a comparison between general patrol and COAST.

Semple and colleagues (2020) found that general patrol officers responded to more calls involving a PMI than a PIC during the pre- and post-implementation periods, whereas COAST responded to more PIC-related calls overall. However, post-implementation, general patrol officers reported significantly more PIC related calls compared to pre-implementation. It was suggested that this could be due to an increase in knowledge on the part of general patrol officers of the different terminology (i.e., what PIC actually refers to) and not necessarily a reflection of changes in call type. When examining call disposition, it was found that COAST provided significantly more resources to clients and made less apprehensions than general patrol officers (however, after implementation, general patrol officers provided significantly more resources to clients and made less apprehensions, which is a very positive sign).

With respect to time spent on calls and cost savings, an analysis of in-progress calls found a significant decrease in time spent on calls involving a PMI post-implementation for 
general patrol officers, which also saved approximately $\$ 50$ on average for calls involving a

PMI. In addition, COAST spent on average less time on calls when compared to general patrol and COAST responding to calls showed significant cost savings. Semple and her colleagues (2020) also examined time spent in the emergency department, however due to the small sample size and infrequency of hospital transportations, it was not viable to evaluate this variable.

\section{The Current Study}

Past research has typically focused on initial assessments of MCIT programs without any follow-up evaluations and long-term tracking. The initial quantitative assessment of the SSPS COAST by Semple and colleagues (2020) showed positive results with respect to some of the short, medium, and long-term goals of the program, though it revealed a need for a more comprehensive evaluation in terms of program fidelity (i.e., is the program being delivered in the way that it is intended to be delivered and are the goals of the program actually being met). The primary objective of the current study is to provide a qualitative assessment of the SSPS COAST, which builds upon the initial quantitative assessment, to examine program fidelity in addition to whether the goals of the program are being met. The evaluation is intended to inform best practices and to improve the ways in which the police in South Simcoe provide services to individuals in crisis. Perceptions of program effectiveness and satisfaction, including the benefits and challenges of the COAST, will be assessed through interviews with various stakeholder groups including the COAST, SSPS frontline officers, senior leaders within SSPS (i.e., Chief of Police, Deputy Chief, and the COAST program supervisor), as well as senior leaders with the two mental health partners (i.e., YSSN and CMHA Barrie).

This study examines the following questions, from the perspective of the stakeholders described above: 
1. Why was the COAST implemented?

2. How does the COAST operate and does the COAST operate as intended? What happens when the COAST does not operate as intended?

3. What are the goals of the COAST and are these goals being accomplished? If the goals are not being achieved, what might explain this?

4. What benefits are associated with the COAST?

5. What challenges are associated with the COAST?

Of course, the views of service users and their families are also critical to the evaluation of the SSPS COAST. As discussed in more detail in the Future Direction section at the end of this thesis, a qualitative assessment of the program focusing on service users will be the final stage of evaluation. Due to time restrictions, this aspect of the evaluation could not be included in the current research. In addition, I did not include any hospital staff participants as part of this phase of the evaluation. The implications of these decisions is discussed in more detail in the Limitations section.

\section{Methodology}

\section{Participants}

This study included a total of 19 participants who belonged to different stakeholder groups: the COAST, SSPS frontline officers, and senior leaders in SSPS, YSSN, and CMHA Barrie. Participants were not compensated for their participation in the study.

COAST. I interviewed three COAST members including the COAST officer and two Crisis Response Workers (CRWs) from the community resource centres (YSSN and CMHA Barrie). The COAST officer is male, and the two CRWs are female. No other demographic 
information was collected. The interview length ranged from 22.35 minutes to 68.38 minutes, with an average of 46.08 minutes $(S D=23.03)$.

Frontline Officers. The goal was to interview 10 frontline officers, but I interviewed 11 frontline officers. To be interviewed, the frontline officers had to be an active-duty police officer who had some contact with COAST in the 6 months before the interview took place. I interviewed six female officers $(54.55 \%)$ and 5 male officers $(45.45 \%)$. At the time of the interviews, the officers had been working with SSPS for an average of four years (these numbers were based on estimated accounts from the officers during the interviews). No other demographic information was collected. There was generally an equal distribution of frontline officers interviewed who worked in the two different jurisdictions that SSPS covers (Innisfil and Bradford). The interview length ranged from 13.17 minutes to 46.53 minutes, with an average of 23.36 minutes $(S D=9.50)$. In general, interview times with frontline officers were relatively short. Some of the interview questions were outside of the knowledge of frontline officers, therefore they were only able to provide detailed responses for questions that were specifically related to frontline officers' relationship to the COAST and the impact the COAST has had for frontline officers.

Senior Leaders. I interviewed three senior leaders from the SPSS including the Chief of Police (male), Deputy Chief (female), and one COAST program supervisor (male). I also interviewed one senior leader from YSSN (male) and one senior leader from CMHA Barrie (female). The interview length ranged from 19.17 minutes to 30.32 minutes, with an average of 26.54 minutes $(S D=4.49)$. 


\section{Measures}

The interview questions were derived from the logic model presented in Figure 1, with the primary intention of assessing program fidelity (i.e., is the program being delivered in the way it was intended to be delivered and are the goals of the program actually being met). Semistructured interviews (using an interview guide for each group of participants) was utilized to maintain consistency between interviews. Interviewees in each group were presented with a set of interview questions that was specific to the group, though there was some overlap in the questions that were posed to each group. For example, topics of general interest across the groups included the core goals of the COAST, the degree to which these goals are being achieved, and the benefits and challenges of the COAST.

The interview questions for the COAST members focused on the goals of the COAST and whether these goals are being met, specific aspects of the COAST and why these aspects are important, the perceived impact that the COAST has had on various stakeholder groups, and the challenges of the COAST (see Appendix A). For frontline officers, interview questions focused on their relationship to, and knowledge of, the COAST, the goals of the COAST and whether these goals are being met, the impact the COAST has had on frontline officers, and the challenges of the COAST from a frontline officer perspective (see Appendix B). Lastly, interview questions for senior leaders in SSPS, YSSN, and CMHA Barrie focused more on "big picture" issues including the reason for implementing the COAST, perceptions of program effectiveness, benefits and challenges of the COAST, as well as the value of program evaluations, like the one being conducted for this thesis (see Appendix C). 


\section{Procedure}

Two different kinds of sampling techniques were utilized for this study. For the COAST and senior leader groups, purposive sampling was utilized. Purposive sampling is a technique in which individuals, or groups of individuals, are selected based on the goals of the research as well as the extent to which they have knowledge of the issue at hand (Ritchie et al., 2014; Schutt, 2006; Teddlie \& Yu, 2007). These particular groups were very limited in terms of the number of individuals who could participate. For example, because there is only one COAST officer, Chief, and Deputy Chief, these participants were inevitably asked to participate in the interviews. Contact information for relevant staff (leaders and CRWs) at the YSSN and CMHA leaders were provided to me by the COAST officer. I contacted them to request their participation. All of these individuals were aware of the study and were expecting to be asked to participate. Because of the nature of these participant groups, and the limited number of possible participants, confidentiality was impossible to maintain within, and in some cases across, the organizations involved in the study. None of the participants expressed concern about this.

For frontline officers, convenience sampling was utilized. The Chief of Police at SSPS distributed a recruitment email to all frontline officers, which briefly described the purpose and requirements of the study (see Appendix D). The recruitment email instructed frontline officers to contact the researcher if they were interested in participating. I then set up interview times for all frontline officers who contacted me expressing their interest in participating.

Regardless of sampling technique, all participation was voluntary. Interviews took place over the span of five days in which the researcher travelled to Barrie; all interviews were conducted in person. Most of the interviews took place at one of the two SSPS stations in Innisfil or Bradford. For the YSSN and CMHA leaders, the researcher conducted the interviews at the 
participants' office location. Before each interview began, participants were given a hard copy of an informed consent form to review and sign to indicate their consent to participate (see Appendix E). At the end of each interview, participants were given a debriefing form (see Appendix F).

\section{Analytical Approach}

Interviews were audio recorded, transcribed verbatim, and thematically analyzed. Thematic analysis provides a systematic yet flexible approach for generating a coding framework with the goal of comparing emerging findings and themes within and across participants (Clarke \& Braun, 2017). This analysis allows for a rich account of the perspectives of participants while also maintaining a structured, well-organized analytical approach (Braun \& Clarke, 2006; King, 2004). In addition, thematic analysis can be used for relatively heterogeneous samples, which is useful for the current study as different themes were likely to emerge across the participant groups (Clarke \& Braun, 2017).

Although there is some previous qualitative research available that evaluated similar programs, an inductive or "data-driven" approach was utilized to allow for a richer description of the entire data set so as to not exclude any of the data or limit potential themes and findings (Braun \& Clarke, 2006). Braun and Clarke's (2006) six-stage thematic analysis process was implemented. The six stages include: (1) becoming familiar with the dataset, (2) generating initial content codes, (3) organizing codes into potential themes, (4) reviewing themes in the context of the broader dataset, (5) defining and naming themes, and finally, (6) reporting the findings (Braun \& Clarke, 2006). This analytical process does not follow a linear trajectory, rather it is characterized by the process of refining the meaning of themes, as well as organizing themes, until they are understood and summarized with ease (Braun \& Clarke, 2006). The 
analytical process was facilitated by the software program NVivo (QSR International, Melbourne, Australia).

Several steps were taken to ensure transparency of the thematic analysis and to adhere to Lincoln and Guba's (1985) suggested qualitative trustworthiness criteria (i.e., credibility, transferability, dependability, and confirmability) to the extent that it was possible. The notion of credibility refers to the accuracy of data interpretation and findings (i.e., are the findings truly reflective of the raw data). Transferability refers to the extent to which the findings can be transferred to other contexts and respondents (i.e., generalizability; Bitsch, 2005; Tobin \& Begley, 2004). Similar to credibility, dependability refers to the extent to which the analytic process (including all decisions and activities) is documented (Bitsch, 2005; Bowen, 2009). Lastly, confirmability refers to the extent to which the findings are truly derived from the data, as well as the degree to which the results are clearly explained (Tobin \& Begley, 2004).

In an effort to adhere to the principle of credibility, member checks, a process by which participants are contacted to ensure the findings accurately reflect their opinions, were completed to minimize researcher bias when interpreting the findings. All participants were sent a condensed version of the findings (see Appendix G) and were asked to let the researcher know if the results were consistent with their views of the COAST and if there were any areas in which the researcher had not addressed. Four participants stated that they had no additional comments regarding the findings. The remainder of the participants did not provide any feedback. In addition, to maintain dependability and confirmability, an audit trail describing the decisionmaking process and activities throughout the interview process and thematic analysis was kept (see Appendix H). Lastly, in relation to transferability, this study utilizes purposive sampling (i.e., a subjective sampling technique used by qualitative researchers to recruit participants who 
meet the qualifying criteria set forth by the researcher and can provide in-depth information about the phenomenon under investigation), which when paired with thick description (i.e., providing a detailed explanation of the methodology and context; Li, 2004), can assist with study replication (Anney, 2014).

\section{Results}

This section will first address how the SSPS COAST was implemented, including the contributions from each partner (i.e., SSPS, YSSN, and CMHA). I will then discuss the themes that were identified within participant responses from the interviews regarding why the COAST was implemented (i.e., the need for the COAST), how the COAST operates (i.e., the activities of the COAST) and whether it operates as intended, the goals of the COAST and whether these goals are being met, the benefits of the COAST, and challenges associated with the COAST. The major themes to emerge from the interviews are presented in Table 1, along with the frequency with which each participant group endorsed the theme. 
Table 1.

Frequency of themes endorsed by each participant group.

\begin{tabular}{|c|c|c|c|c|}
\hline Themes & $\begin{array}{l}\text { Total Frequency } \\
\quad(n=19)\end{array}$ & $\begin{array}{c}\text { COAST } \\
(n=3)\end{array}$ & $\begin{array}{l}\text { Senior Leaders } \\
\quad(n=5)\end{array}$ & $\begin{array}{c}\text { Frontline } \\
(n=11)\end{array}$ \\
\hline \multicolumn{5}{|l|}{ Need for the COAST } \\
\hline Contact with police & 13 & 3 & 1 & 9 \\
\hline A lot of mental health calls & 11 & 1 & 2 & 8 \\
\hline Insufficient access to services & 9 & 3 & 3 & 3 \\
\hline Frontline not equipped & 16 & 2 & 3 & 11 \\
\hline Unnecessary apprehensions & 8 & 1 & 2 & 5 \\
\hline \multicolumn{5}{|l|}{ COAST activities } \\
\hline Training & 13 & 3 & 3 & 7 \\
\hline Follow-ups & 13 & 3 & 4 & 6 \\
\hline Connect to resources & 19 & 3 & 5 & 11 \\
\hline De-escalation & 10 & 2 & 4 & 4 \\
\hline ED Diversion & 11 & 3 & 5 & 3 \\
\hline Program monitoring & 12 & 3 & 5 & 4 \\
\hline \multicolumn{5}{|l|}{ COAST goals } \\
\hline Free up frontline officers & 14 & 2 & 4 & 8 \\
\hline Support client and family & 13 & 3 & 5 & 5 \\
\hline Reduce recidivism & 8 & 1 & 3 & 4 \\
\hline Increase officer awareness & 16 & 3 & 4 & 9 \\
\hline Building relationships & 5 & 1 & 4 & 0 \\
\hline \multicolumn{5}{|l|}{ Benefits of the COAST } \\
\hline Support frontline & 16 & 3 & 5 & 8 \\
\hline Officer and crisis worker & 14 & 2 & 3 & 9 \\
\hline Services getting used & 11 & 2 & 2 & 7 \\
\hline Decriminalization & 15 & 3 & 3 & 9 \\
\hline Provide better service & 10 & 1 & 2 & 7 \\
\hline Bridge gap & 9 & 3 & 2 & 4 \\
\hline
\end{tabular}


CRISIS INTERVENTION TEAMS

\section{Coverage}

Funding

Program awareness

Relationship with hospitals

$\begin{array}{cccc}18 & 3 & 4 & 11 \\ 6 & 1 & 3 & 2 \\ 6 & 3 & 1 & 2 \\ 7 & 2 & 3 & 2\end{array}$




\section{COAST Implementation}

I wanted to establish generally how the COAST was implemented and how the program is funded, as well as the contributions of each partner (i.e., SSPS, YSSN, and CMHA Barrie). This information was gathered during the interviews with senior leaders from SSPS, YSSN, and CMHA Barrie.

The COAST was first implemented in September 2017 when a partial Policing Effectiveness and Modernization (PEM) grant was given to SSPS to kickstart the program. The PEM grant, effective as of April 1, 2017, was created by the Ministry of Community Safety and Correctional Services (MCSCS) to address risk factors in the community, such as mental health, in hopes that it would reduce the reliance on police in responding to social challenges that are not criminal in nature (Ontario Association of Chiefs of Police, 2017). This grant was available to Ontario municipal police services as well as Ontario Provincial Police (OPP) contract services. The two mental health partnering agencies received funding through their respective Local Health Integration Networks (LHIN). LHINs were established by the Government of Ontario to plan, coordinate, integrate, and fund health services at the local level (Central West LHIN, 2014). There are fourteen LHINs in Ontario.

In terms of each partners individual contributions to the COAST, SSPS is responsible for providing the COAST officer, an unmarked minivan, as well as the vests for the crisis response workers (CRWs) and any other necessary policing equipment. YSSN provides a CRW three fulltime days per week and CMHA Barrie provides a CRW two full-time days per week. At the time of the interviews, the COAST program operated five days per week. The COAST officer works four full-time days, utilizing an alternate COAST officer on the fifth day.

\section{Need for the COAST}


During the interviews it became clear that there were several factors that reflected the need for the COAST program. These include the contact between individuals in crisis and the police, the large number of mental health calls that the police receive, insufficient access to services in the communities for people in crisis, and the fact that frontline officers are not equipped to deal with crisis calls, often resulting in unnecessary apprehensions.

Contact with police. Many participants $(n=13)$ described the police as the first point of contact when individuals are experiencing crises, which was often based on the fact that police are the only service that is available to community members $24 / 7$. COAST members explained that "We have found that generally, our calls that are crisis-related, for lack of a better word or term rather, are basically there's no other resources to be found by these persons in crisis, or to be accessed" (Participant 2- COAST Officer). The same participant further suggested that individuals in crisis have "Constant police contact by virtue of being around 24/7" and that "911 is seemingly their only option."

This rationale was consistent with the views of frontline officers. One officer stated, "I think every police agency needs to have COAST. $100 \%$. Because we're the only thing that's open 24 hours, that you can call... when people are in crisis, they call 911" (Participant 9frontline officer). Another frontline officer expressed that "officers always have attended for mental health calls, always" (Participant 19- frontline officer).

In addition, reflecting the fact that police are the ones that inevitably will have to respond to crisis calls, one of the SSPS senior leaders made it clear that, "If we don't do this partnership, we're still going to be spending budget dollars, but we're going to be in a reactive mode, responding to those crisis calls, and that's going to demand our service either way" (Participant 4- SSPS Chief of Police). 
A lot of mental health calls. More than half of the participants $(n=10)$ agreed that the police receive a large number of mental health and crisis related calls, and many noted that this number is only increasing. A COAST member stated, "Our rates of crisis-related calls are not decreasing. We have a large population increase, which could explain that as well. And like I had mentioned prior, the [community] services are lacking in both Bradford and Innisfil. We're filling that service gap, sadly" (Participant 2- COAST Officer).

Several frontline officers also reflected on the number of mental health related calls they attend. One officer said, “almost every shift you're going to some call where there's some mental health component" (Participant 9- frontline officer). Another officer had stated:

"We have a ton of mental health calls. And I don't think it's even specific to here, but I was definitely shocked when I came here, how prevalent it is. And I think I looked at the year-end report, the one year, and I was like, wow. I had no idea that it was such a high percentage of our calls, but it just is" (Participant 17-frontline officer).

One of the senior leaders also mentioned that, "last month, we had 46 calls for service with our COAST unit, and that's typical of a month" (Participant 5- SSPS Deputy Chief), indicating at least one mental health and/or crisis call a day.

Insufficient access to community/mental health services. Many participants $(n=9)$ noted not only the lack of community/mental health services available in Innisfil and Bradford, but also the barriers in accessing the services that are available, such as the need for transportation. One of the COAST members stated:

"I don't think it's sufficient right now as we have a small hub of CMHA workers. There's a psychotherapist. There's brief service, case management and addictions. 
But that just recently was provided to Innisfil in the last two years. That's about all we have for mental health. And if you don't have transportation because of the rural nature of Innisfil, it's a big barrier to get to those services" (Participant 1COAST CRW).

Describing the lack of services as a reason for individuals calling the police when in crisis, another COAST member stated:

"We have no shelters. We have very little, if any, supports for addiction, homelessness. All of these social determinants of social disorder and community wellness are lacking. We have found that generally, our calls that are crisisrelated, for lack of a better word or term rather, are basically there's no other resources to be found by these persons in crisis, or to be accessed" (Participant 2COAST Officer).

Frontline officers also indicated that community resources are lacking, as well as the need for transportation to access the services that do exist. One officer mentioned that, "I'm out of Bradford. I don't do anything in the north, really. But I find that people in the community of Bradford don't have local resources and a lot of them don't have the means to get to York Region” (Participant 16- frontline officer).

Senior leaders also attributed the barrier to services as a consequence of the current LHIN system. One senior leader said that, "the problem with our LHIN system, and as you probably already know, the division within counties doesn't align with political or policing divisions. And it just makes it for chaos to get the person who needs resources, to the resources" (Participant 6SSPS COAST Supervisor). Another senior leader stated: 
"Our LHIN for the time being, its central LHIN covers North, all of York region, and then it goes up into South Simcoe. And it's a very odd map. It does cover Alliston, but then it cuts back down, covers Bradford. That is more of a rural area. There are definitely less resources. The closest hospital is in Newmarket, which isn't far for Bradford but it's a long way for Alliston. There's not a lot of services of this nature" (Participant 7- YSSN Senior Leader).

Frontline not equipped. In the context of the need for the COAST, nearly all participants $(n=16)$ expressed that frontline officers are not equipped to appropriately handle mental health and crisis related calls. This was often associated with factors such as a lack of training, education, and knowledge. When asked about frontline officers' abilities to handle crisis calls, one COAST member stated:

“they're still not equipped to deal with severe mental health issues. As much as they're ahead of the curve, there's still a lot of education and training that they need to have to be equipped to deal with these situations. They're doing the best they can, but again, police aren't trained or educated for this scenario. They're going in blind" (Participant 1- COAST CRW).

All frontline officers also mentioned a deficit in their own abilities to handle crisis calls. One officer said:

"I feel that COAST is trying to bridge the gap for a lot of the things that we lack in either resources or even knowledge. They have a particular specific skillset and knowledge of not only referrals, but the system, how people can be helped, better than a frontline officer. Really, we're limited with what we can do" (Participant 11- frontline officer). 
Senior leaders also indicated that police are not necessarily the best response for matters relating to mental illness. For example, one of the SSPS senior leaders stated:

“I think, policing, what's happened is we've taken on a lot of responsibilities, without necessarily being our core responsibility... If our core responsibility, with respect to mental health issues, is to ensure the safety of all the people involved, then we may not be the best people to then help that person cope with their mental health issue" (Participant 4- SSPS Chief of Police).

Unnecessary apprehensions. With respect to frontline officers not being equipped to appropriately handle crisis related calls, some participants $(n=8)$ specified a tendency for frontline officers to apprehend individuals in crisis from a liability standpoint. For example, one COAST member mentioned, "The area that still needs a lot of work for the uniformed officers is a tendency to apprehend. This a generalisation. I'm not sure that they're still yet comfortable working toward a safety plan and having confidence in the safety plan in terms of diversion" (Participant 1- COAST CRW).

Frontline officers also disclosed their tendency to apprehend with one officer stating: "Like, if I'm apprehending somebody because they meet the criteria, sometimes I know that COAST would not be apprehending this person. But I don't have the backup to say, no, this is not... I don't need to take this person to the hospital. But just the basic training that I have, yes, I do need to take this person to hospital" (Participant 13- frontline officer).

This view was also consistent with senior leaders. For example, one participant said: "Historically and typically in a police model, a person in crisis that exhibits the behaviours that would promote, if you will, or guide an officer to apprehend them under the Mental Health Act 
because they're a harm to themselves or others. They would be apprehended" (Participant 6SSPS COAST Supervisor). Furthermore, another senior leader mentioned that, "We know from doing COAST, they go to the hospital, it's a lot of time and effort and really nothing happens. It's not the appropriate place for them to be. And we also know lots of police have a history of apprehending because they're not sure what else to do" (Participant 8- CMHA Senior Leader).

\section{COAST Activities}

One of the goals of this research was to assess how the COAST operates and whether the program is operating as intended according to the activities indicated in the COAST logic model. Throughout the interviews, all participants $(n=19)$ described one or more activities that the COAST engages in, each of which aligned with activities included in the logic model. In terms of the COAST operating as intended, the COAST does seem to engage in each of the activities outlined in the logic model. However, due to a lack of resources, the COAST isn't always available to attend crisis calls, even when they are on duty, meaning frontline officers are often still handling these calls. As outlined in previous sections, frontline officers are typically illequipped to respond appropriately to crisis calls, which may mean that de-escalation and ED diversion are not always possible, and some individuals in crisis may not be flagged for a followup from the COAST or provided with appropriate community resource information.

Training. Many participants $(n=13)$ indicated that the COAST has provided various information sessions to frontline officers in regard to mental health, as well as the COAST program itself. One of the COAST members said:

"I know [COAST Officer] does information sessions on the regular. Not myself more so because he works at the station, but I will do that with him. He also does information sessions on other issues like the transgender community, things like 
that that are becoming more prevalent and are sensitive issues and that police need to have a little more education around" (Participant 1- COAST CRW).

The COAST officer also indicated the ability to train officers formally and informally, for example:

"by virtue of being a smaller-sized agency, we have the ability as the COAST team to formally and informally educate and train new officers... I've had numerous opportunities to debrief officers, both on scene and just shortly thereafter after a call, as to why we did what we did, what the resources were, what this person may be experiencing in terms of a mental health disorder, condition, etc.” (Participant 2- COAST Officer).

Frontline officers also talked about the training they’ve received from the COAST. One officer said, "our COAST guy has done presentations for us where it brings a different light to what people might be going through as to what I have thought before in the past" (Participant 14frontline officer). When asked about their frontline officers abilities to handle crisis calls, another officer mentioned that, "I believe that it's definitely getting better through the training that our COAST officer has been able to provide us in service training and stuff like that" (Participant 10frontline officer).

Lastly, senior leaders also mentioned training frontline officers. For example, one senior leader stated:

"Part of our contribution was to train all of our frontline officers. So, not just having this one specialist area, but to train all the other frontline officers on some of the diagnoses around mental health, mental illness, some of the terminologies they should be using, how they should be reporting incidents. If the COAST 
officer was working, then how to utilise that COAST service. If they're not working, then how to deal with it when they're not working. Providing the officer some additional skills" (Participant 4- SSPS Chief of Police).

Although it was clear that the COAST program provides training to frontline officers, some officers felt there could still be more training provided to frontline regarding the COAST program itself. For example, some frontline officers mentioned that they were not fully aware of the goals of COAST $(n=2)$ or how the COAST operates (e.g., whether or not COAST is supposed to take over frontline apprehensions; $n=4)$.

Follow-ups. Many participants $(n=13)$ acknowledged the COAST's involvement in conducting follow-ups with service users who had come into contact with the police. In addition, the importance of follow-ups as one of the COAST's duties was often recognized as an essential piece in reducing future contact with the police. For example, one of the COAST members stated:

“There's two types of follow-ups we do. Myself and [COAST Officer], we respond to every single mental health call that comes in through dispatch. We make sure we follow up so that nobody's missed. But we also have proactive follow-ups. Maybe a client that we know is struggling or having a difficult time, we may have met with them two days before. But we know if we keep in touch and we try to stabilise, that that might be helpful in reducing the chances of having contact with frontline officers or having to go to the hospital" (Participant 1- COAST CRW).

Frontline officers also felt that follow-ups were a significant tool in reducing police contact. One officer mentioned: 
“They're not only for responding to actual persons in crisis, but I know there's definitely people who require follow up... there's definitely the need for follow up, to make sure that people get the resources they need, so that they don't get to that point where we're only helping them when they find themselves in crisis. So, if we can help stop someone from getting up to ten out of ten, if we can help them along the way, then I think that would definitely help" (Participant 11- frontline officer).

This view was consistent with senior leader participants as well. For example, one senior leader said:

"So, you might have a really crappy day, and we deal with you, but we're not forgetting you. And you go into a queue, and our COAST follows up and says, hey, how are you doing? Have you followed up on this? So, we're never letting them feel isolated, that we are here, we are caring. And they're doing that to actually drop our person-in-crisis calls, because they're doing that constant follow up" (Participant 5- SSPS Deputy Chief).

Lastly, a few participants $(n=3)$ expressed the importance of follow-ups as an opportunity to provide service users with information regarding resources in a calmer setting, as individuals are less likely to take that information when in an acute state of crisis.

Connect to resources. All participants $(n=19)$ discussed the COAST's abilities to not only refer service users to various resources and service providers in the community, but also to facilitate that connection. In addition, the COAST was often recognized for their knowledge of the available resources, which frontline officers seemed to be lacking. One COAST member said, "We connect people to the supports that are most appropriate to them. Whether it's 
behavioural, emotional, could be addiction-related, could be somewhere in between, whether it's community support. And we try to connect them to the best of our ability" (Participant 2COAST Officer).

One of the frontline officers mentioned that, "he [the COAST Officer] has more resources than we do. He goes to all these different events where he can learn, he knows the right people" (Participant 14- frontline officer) and another officer also said, "They have a lot of connections with resources in the community, so they can fast-track people into those programs or into some of the resources that are out there" (Participant 15- frontline officer).

Senior leader participants held similar views regarding the COAST's ability to connect service users to the resources. For example, a senior leader stated:

"I see the COAST program making longer-term connections to people in crisis. So, they're linking you to the different social services, where you don't really need to go to the emergency room. The crisis workers and our COAST officer are very familiar with everything that's offered, whether it be housing that has brought you down, the stress of finances. They'll get to the right service" (Participant 5- SSPS Deputy Chief).

Furthermore, some participants $(n=4)$ mentioned that the COAST can assist service users to navigate the healthcare system, which was noted to be "chaotic" and "complex", potentially discouraging some individuals from seeking help.

De-escalation. There were several mentions $(n=10)$ of the COAST's role in deescalating crisis situations making it clear that this was one of their main priorities with the goal of avoiding the emergency department (ED). One of the COAST members said, "Our bread and butter are, the first one would be the live crisis calls with the goal to de-escalate and to find an 
emergency department diversion when appropriate" (Participant 2- COAST Officer). Another COAST member also mentioned, "For short term, the goals of COAST, again, immediate response. We're trying to de-escalate the client" (Participant 1- COAST CRW).

Frontline officers also acknowledged the role of COAST in de-escalating crisis situations, which they often attributed to their discreet nature. For example, one officer stated, "Like I said, no police presence, with their showing up not in uniform and not in a car, which helps keep things on a de-escalation level" (Participant 15- frontline officer), while another officer said, "Sometimes it's also a matter of knowing that that officer is there, the one that works with the crisis worker, who is not in uniform. Because we all know that even our presence being there in uniform can trigger somebody or escalate a situation" (Participant 11- frontline officer).

The role of de-escalation was also recognized by senior leader participants. For example, a senior leader mentioned that, "When you have a mental health worker present on a COAST team they can use those skills to de-escalate individuals, rather than police responding in the way traditionally that they have" (Participant 8- CMHA Senior Leader). In addition, another senior leader said, "Often within hours, that person in crisis are now de-escalated out of crisis, and already starting to set up appointments with referrals and supports. So, the individual, the person in crisis, gets help immediately" (Participant 6- SSPS COAST Supervisor).

ED Diversion. The COAST is geared towards ED diversion and keeping individuals out of the hospital, which was noted by several participants $(n=11)$. It was thought by many that the hospital is often not an appropriate place for service users to be, rather they should be supported in the community. A COAST member stated:

"Short term, our priority is emergency department diversions, EDDs. And that is to have persons in crisis, provide them with an outcome that is most suitable for 
them. That meaning they not necessarily going to the hospital, most definitely not being connected or contacting the criminal justice system in the sense of charges if there's more appropriate outcomes, depending on context. In terms of short term, keeping people out of the hospital when they could be better served by community-based supports" (Participant 2- COAST Officer).

These sentiments were also recognized by frontline officers. For example, one officer said:

"My understanding is that they are trying to keep individuals out of hospitals unless it's absolutely necessary. And provide people with the supports that are appropriate for their needs. And to not just have a kneejerk reaction of sending people to emerge, to be apprehended, to be formed, to not be formed. To be kicked back out on the street with no further ahead" (Participant 9- frontline officer).

Senior leaders also addressed the importance of ED diversion. One senior leader stated:

"The major goals: To divert people in crisis from the emergency room department, because the emergency room department is short lived. It's a bandaid solution. Whether you're in there for two hours or you're committed, at the end of the day, you leave the hospital, and you're out of sight, out of mind" (Participant 5- SSPS Deputy Chief).

This participant then continued to say, "I think we're better equipped. I think we know our social services, and we know our business, and we know how to redirect people, so they don't go into that emergency room." 
Program Monitoring. Many participants $(n=12)$ mentioned the monitoring and tracking of the COAST program as a core activity of the COAST. It was typically the COAST members and senior leader participants that discussed program monitoring in more detail. Program monitoring was thought to be important in both supporting the need for the program, but also for revealing areas in which improvements could be made. One COAST member stated:

"We do evaluate the programme every three months as of right now, for the last year, we calculate stats. On my side, we have certain stats that we're hitting, ER diversions, how many live calls there are, how many follow-ups we do, how many referrals to services, things like that. And we do them every three months. Compare them to the last month of what our expectations are, see if there's any gaps or anything that we should be doing different" (Participant 1- COAST CRW).

When discussing program evaluations such as this report, one senior leader said: "So, if there's something we're not doing that we should be doing, and the research shows that, then we can then adjust our programme. Or if we are doing a really good job, again, an opportunity to market that in the community and say, this is the service that's now being validated by an external agency through a research team to say, yes, it's working, and then that helps us market what we're doing better, right? We can say, it's not just us telling you it works. Somebody has said it works, too" (Participant 4- SSPS Chief of Police).

Although frontline officers spoke in less detail about program monitoring, there was acknowledgment of various statistics and reports being kept. For example, one officer mentioned: 
"I know that there's been like articles published, about like numbers, how many calls they've gone to, reducing wait times and things like that, I think it gives the bosses an opportunity to... optics, right? Or sometimes speak really good that... Two years ago, again, we didn't have COAST, now we have COAST, this is what it did in the first year" (Participant 18- frontline officer).

Other Activities. In terms of the activities outlined in the logic model, there were two activities that were only discussed specifically by the COAST members, which included the monitoring of all incoming crisis calls and participation in community engagement events. COAST members made it clear that they do monitor and track all crisis calls, whether that be live calls or after the fact should they be unable to attend. For example, one of the COAST members said: "If I'm not on the call, I can follow up. I also have the advantage of being able to review, which I do. I review every single crisis call” (Participant 2- COAST officer). In addition, COAST members also advised that they do participate in community engagement events. One COAST member described some of these events:

"There's, through the school, sometimes they have mental health programme days. We've done education through CMHA. We've done them through, recently, the solicitor general or somebody had a meeting that COAST went to and described what we do. Again, we've gone to CAS [Children's Aid Society]" (Participant 1- COAST CRW).

Because these two activities were only briefly discussed by COAST members I did not include these in the final themes, however, I felt it was important to at least address the fact that the COAST does participate in these activities.

\section{COAST Goals}


Throughout the interviews it became evident that there are several goals of the COAST involving the various stakeholders, many of which are being achieved. These goals included freeing-up frontline officer resources, supporting service users and their families, reducing recidivism, increasing frontline officer awareness regarding mental health and crisis issues, and building better working relationships between SSPS, YSSN, and CMHA.

Free up frontline officers. A large majority of participants $(n=14)$ indicated that the COAST is intended to help alleviate frontline resources. Because frontline officers have a tendency to apprehend and wait times at the hospital are often hours long, crisis calls can be very time consuming for officers, which then takes away from their ability to attend other calls for service. One COAST member said:

"We try to relieve the pressure on the frontline officers, the road officers, because there's a lot of time it takes. If an officer doesn't have the education to say, maybe that person doesn't need to go to hospital, there's four to six hours of transport and then sitting at the hospital as well, which is money" (Participant 1- COAST CRW).

The same participant continued to say, "reducing police time at the hospital is huge for police officers... the number one positive would be keeping those officers on the road where they need to be."

Frontline officers strongly agreed that the inception of COAST was great for alleviating frontline resources. For example, one officer said:

"So, if two people are required to apprehend an individual, then that's two people off the road. So, if COAST is there and they're able to do all the follow-up and take care of everything for frontline and pick up where we stop, then resources are 
available. So, I think, especially for our small services, yes, it's important” (Participant 13- frontline officer).

Another officer shared a similar view: "We'd have a frontline officer in the hospital for three, four or five hours where now they can go back on the road" (Participant 19- frontline officer). Senior leaders also recognized the importance of freeing up frontline as one of the main goals of COAST. One senior leader stated:

"So, the initial goals would've been enhanced response for our frontline officers. So, not having two officers go there and spend multiple hours dealing with mental health crisis calls, spending time in hospitals and longer wait times, and then having the person released, and then the frustration for the officers... So, now, instead of having two officers for four hours tied up, we can now have one officer maybe tied up for four hours as well, but that's less than having two officers tied up, and they're working with a crisis worker. So, some goals from efficiency standpoint" (Participant 4- SSPS Chief of Police).

Although most of the participants acknowledged the COASTs ability to alleviate frontline officers, it was often mentioned that due to the lack of resources for the COAST, and the fact that they are not available $24 / 7$, frontline officers were still largely the ones handling crisis calls. For example, one frontline officer said:

"There are certain advantages with things like COAST, but the caveat to that is COAST has to be available. So, that's one of the things that I personally have found, that when they're available, it's great. They're able to provide an excellent service for us and determine whether or not someone's in crisis. But at the same 
time, it's determining whether or not they're even available" (Participant 11frontline officer).

Another frontline officer mentioned: "I find that when we get a call for someone in crisis, COAST is not available" (Participant 16- frontline officer). The lack of coverage is discussed in more detail in the COAST challenges section below.

Support client and family. Many participants $(n=13)$ shared the sentiment that the COAST provides enhanced support for services users and their families, which is ultimately one of the main goals of the COAST. Many participants disclosed receiving positive feedback about the COAST and the ways in which users were supported. One COAST member said, "On the families and the service users, it's been great. They feel supported. They feel heard. They feel validated. They don't feel alone. They know when they're having a crisis, we always give our contact information if they need a follow-up, if they need us to come and touch base" (Participant 2- COAST Officer).

When discussing a specific crisis call that COAST had attended, one frontline officer mentioned: “The mother went from like, hey, my son's going to the hospital because he's going to kill himself, to hey, my son just joined the volleyball team. So definitely, for families, I'd say it's a huge, huge impact on that more than anybody, like the person in crisis and the family, biggest" (Participant 19- frontline officer).

Senior leaders also discussed the COAST's ability to provide a certain level of expertise and enhanced support. For example, one senior leader said, "I think for service users, it's not only bringing the support to them, but it's bringing a certain amount of information, knowledge on the system" (Participant 7- YSSN Senior Leader). Another senior leader also stated: 
"I think it provides support to the families. It gives them someone to help them navigate the system, which is a huge barrier for people that are unwell, A. And then, B, people that are trying to support them. Navigation of the system is, I would say, one of the top five things that we deal with" (Participant 8- CMHA Senior Leader).

Reduce recidivism. One of the goals of the COAST is to reduce recurrence rates by steering service users to more appropriate resources within the community. Based on the interviews, this goal is presumably being met. Some participants $(n=8)$ discussed the fact that since the implementation of COAST, crisis recidivism is reducing and the police are receiving less re-occurring calls from the same individuals. This was often attributed to the COAST conducting follow-ups and connecting services users to the resources in their community. For example, one COAST member stated:

"We also have proactive follow-ups. Maybe a client that we know is struggling or having a difficult time, we may have met with them two days before. But we know if we keep in touch and we try to stabilise, that that might be helpful in reducing the chances of having contact with frontline officers" (Participant 1COAST CRW).

Frontline officers also felt that they were receiving less re-occurring calls:

"I know COAST does a lot of follow-ups with a lot of our calls that we deal with. We send stuff to COAST and then they do their follow-ups. I think it helps because a lot of times we don't end up having reoccurring calls because they're [the client] is into programmes or dealing with their resources or they've been put in contact with other hospitals or doctors or what we have within the community. 
A lot of times we don't get those second and third calls" (Participant 15- frontline officer).

The views of senior leader participants were consistent as well. One senior leader mentioned, "We're seeing a reduction of crisis recidivism. Often in the past we'd have reoccurring calls from the same individuals going into crisis the very next day. The same day" (Participant 6- SSPS COAST Supervisor). They then continued to say, "That likelihood of recidivism of that crisis is less, because there's that connection made. So, that person now has a future appointment. Now has a future contact. Now has a hope."

Increase officer awareness. Another goal of the COAST program is to educate frontline officers regarding mental health and crisis intervention. Nearly all participants $(n=16)$ expressed an increased awareness among frontline officers in handling crisis calls. Many frontline officers themselves felt that the COAST had helped them learn how to respond more appropriately to crisis calls and had also increased their own knowledge of the available resources in their community. One COAST member mentioned, "People [frontline officers] are now using the term person in crisis. They're going from a person-centred approach now where it's not schizophrenia or alcoholic. The person with schizophrenia. The person with alcoholism" (Participant 2COAST Officer). Another COAST member said:

"I think they're quite well educated. When we get a report from officers when we're not on shift, for example the weekends, the information is good. Often times they end the report saying they've talked about COAST and they've given the 310-COPE contact information as they leave the situation" (Participant 3COAST CRW). 
Frontline officers discussed how their own abilities and knowledge in handling crisis calls have improved due to the COAST. For example, one officer stated:

"When COAST and the crisis worker show up on the scene, we can step back, see what questions are being asked, see what behaviours are being exhibited, see what the concerns are, see what the resources are. So, the more you hang around and listen to that dialogue, the more you're learning, the more you can pull from that and then apply it to another situation where maybe COAST isn't available immediately" (Participant 9- frontline officer).

Another frontline officer also mentioned, "It's definitely major awareness as far as gauging what's actual crisis and what can be sent to COAST officers, and what they can handle. What's immediate and what's stuff that... Resources they've given us, to provide to them. It's definitely made you more aware of what's out there" (Participant 15- frontline officer).

Senior leaders also talked about the increased awareness among frontline officers. One senior leader said, "I think the impact on COAST here is there's been a growing awareness amongst the officers. We are, I think, better trained, more aware when dealing with people in crisis than we were two years ago" (Participant 5- SSPS Deputy Chief). Another senior leader also voiced that, "I'm hearing from the officers; they feel more confident to deal with the calls. The training is getting used" (Participant 4- SSPS Chief of Police).

Although the majority of frontline officers felt that their knowledge and skills in handling crisis calls had improved, some officers still felt that they needed more clarity about the resources available in the community $(n=3)$. The general consensus in regard to the goal of increasing officer awareness and knowledge concerning mental health, and improving their 
abilities in handling crisis calls, was that this goal is being met, but ongoing training for frontlines officers should continue.

Building relationships. Lastly, one of the major objectives of the COAST is to improve the working relationship between police and mental health service providers who have traditionally been working in silos. COAST members and senior leader participants $(n=5)$ agreed that the COAST had improved the partnership between these two entities. Frontline officers did not speak to this matter.

One COAST member talked about breaking down barriers between mental health service providers and the police: "We've been able to build bridges, break down some boundaries between the police and the mental health or social services domains, breaking down these silos. We're working collaboratively with each other" (Participant 2- COAST Officer). The same participant continued to say:

“There's a greater acceptance of the mental health worker, of the crisis response worker, because they are immersed in the police culture. They're not an outsider coming in into, quote unquote, police business. They are part of the team. We've removed that outlier status already with that person”.

Senior leaders discussed an increased understanding between police and mental health service providers. For example, one senior leader participant stated, "I think it's enhanced the relationship. Again, we're now working closer with the people that are responsible for the wellbeing of the individuals, being the crisis workers. I think it's helped our people understand the world that the crisis workers work in" (Participant 4- Chief of Police). Another senior leader also said, "It has built a wonderful working relationship with these two entities, that they both contribute a crisis worker to the COAST programme, and it seems to be working. It really is a 
positive relationship with both social services" (Participant 5- SSPS Deputy Chief). A third senior leader mentioned:

"I think it does bleed into the other profession, in both ways too. Because, for social workers and police, probably historically when they're in York University and seeing them as perhaps someone of the enemy or authoritarian, realising that's not necessarily the case. And it really builds a good relationship, I know, with all of our staff that work on these teams and we have six of them. They really enjoy the relationships that they've built with the place" (Participant 7- YSSN Senior Leader).

The same participant continued to say, "it [the COAST] has definitely provided an avenue for us to work better together for those people in that community".

Based on the perspectives of the COAST and senior leader participants, the goal of building better partnerships with YSSN and CMHA is being achieved. However, in addition to the working relationships with YSSN and CMHA, one of the goals of the COAST is to improve their partnership with the local hospitals. It was clear from the interviews that the relationship with the local hospitals requires much improvement and that this particular goal is not being met. The relationship with the hospitals is discussed in more detail in the COAST Challenges section below.

\section{Benefits of the COAST}

During the interviews, participants spoke to the many benefits of the COAST for the various stakeholder groups. Benefits of the COAST included the support it provides to frontline officers, the presence of a mental health expert for service users and their families, the increased usage of the mental health services available in the community, the decriminalization of 
individuals in crisis, providing a better service to individuals in the community, and the bridging of a service gap between police and mental health care.

Support frontline. A large majority of participants $(n=16)$ expressed that the COAST provides support to frontline officers in the sense that it gives them an additional tool or option to utilize when responding to crisis calls. Many participants mentioned that even when COAST is not able to attend a live crisis call, frontline officers are able to call the COAST for advice or resource information. For example, one COAST member said, “And even sometimes if we're not required for the call, they might call us for advice or information or education around something. It's again, given them another layer of support for their calls as well" (Participant 1- COAST CRW). Another COAST member stated:

“He'll [COAST Officer] get a call from an officer on-scene. [COAST Officer], this is what we're seeing. I don't think it's an apprehension, but looks like he needs to... So we consult with the officer. Well, we could try COPE. We could try Barrie Crisis, there's shelters. So we can give resources to the officer if we're unable to attend" (Participant 3- COAST CRW).

Many frontline officers voiced that they will contact the COAST for assistance. For example, one officer said, “There's almost always, [COAST Officer], do you have a second? And we'll just bounce something off of him or his workers because of the resources that they have as well as him" (Participant 19- frontline officer). Another officer stated:

"It's just the support. Having somebody to not only be there and back you up, but also somebody to go to. Like, hey, I had this call, this is what happened, what do you think? Did I do okay? Should I have done something differently? And so, 
having somebody to go to and talk about that with is very positive" (Participant 13- frontline officer).

Senior leaders also discussed the fact that even when COAST is unable to respond to a crisis call, frontline officers feel better leaving the call knowing that the COAST will follow-up with the service user. For example, one senior leader stated:

"I think it provides support to police, like, in dealing with people. Because COAST is not a 24-hour-a-day programme. So, it offers them an alternative. So, if they've dealt with somebody on a Friday evening and COAST isn't in until Monday, they at least know, oh, okay, COAST can follow up on Monday. I'm sure, and I know it does, it feels better to know they have an option and that the person's not just left with nothing” (Participant 8- CMHA Senior Leader).

Lastly, some participants, including the COAST officer himself, expressed that the COAST officer has made himself available to frontline officers to assist with crisis calls while off-duty $(n=5)$. This was generally talked about in a positive light.

Officer and crisis worker. Several participants $(n=13)$ specifically mentioned the importance of the co-responding model, having both the officer and crisis response worker attending crisis calls. For example, many frontline officers spoke about the advantage of having the crisis worker present, not only for the level of expertise that they bring, but also because the interaction with the service user becomes more personable. For example, one officer mentioned: "I think really it's just, one, the combination of the police officer and the crisis worker. You're not having that big, intimidating police presence with that person. So, I think that they're [service users] able to become a little bit more vulnerable and talk about their problems" (Participant 12- frontline officer). 
Another officer stated:

"I think having a crisis worker, being able to, it personalises the interaction with anybody that they're dealing with. It's, oh you're a police officer, you don't know anything about mental health... Well, I have my crisis worker here, and he's gone to school for this, and this is what they do, this is their job. We're working together with police and with the community and this is what we have. And then people say, oh, okay" (Participant 15- frontline officer).

This sentiment was also consistent with senior leaders. For example, one senior leader said:

"It's not just one thing, but it's the synergy of having a plainclothes officer with a crisis worker attending those calls when it's safe to do so, in an unmarked vehicle. So, you're removing barriers. Immediately when you walk in, people are willing to talk to you. So, you've conquered the number one block of not wanting to talk to the police" (Participant 6- SSPS COAST Supervisor).

Another senior leader similarly stated, "I think people feel, and I know families feel much better knowing that there's a crisis worker with an officer when it comes to calling police, because people are often hesitant about calling police regarding mental health" (Participant 8- CMHA Senior Leader). The same participant also talked about the advantage of having an officer present, which allows the mental health professionals to do their job in a safe environment:

“Social workers don’t just stroll into unsafe situations or unknown situations. That doesn't happen. So, we're able to get the worker to the person. And I feel like that's one of the biggest things with COAST is that you are able to get to someone who would not otherwise go anywhere." 
One COAST member also mentioned the safety that the co-response model provides for the crisis response workers: "When we go, he [COAST Officer] can make sure the scene is safe so that I can do my job more effectively. And it imparts safety on all parties there and we're safe, the client's safe. That aspect is really important" (Participant 1- COAST CRW).

Services getting used. Roughly half of the participants $(n=11)$ stated that the various service providers and mental health resources in the community were likely seeing a greater utilization of their services due to the increased number of referrals happening with the inception of the COAST Program. Some participants also mentioned that this could result in more funding for these service providers due to the increased usage. For example, one COAST member stated: "Honestly, we [CMHA] are busy. We have a lot of calls and a lot of people. But as much as that workload goes up, these are people that would otherwise probably be going to hospital or in contact with the law, which is not an appropriate place for them to be. The workload would absolutely... It has to go up. I've done a tonne of referrals" (Participant 1- COAST CRW).

The same participant continued to say:

"With the increased workload, hopefully more funding comes in and more services are expanded. Specifically, in Innisfil, hopefully the need can be shown that there's not enough services and the people who are working them are overloaded. That just shows the need that's there."

Similarly, another COAST member said, "An increased workload or an increased wait list has an upside to them because it adds to the weight of funding requests" (Participant 3- COAST CRW).

Frontline officers also discussed the increased usage of the resources in the community. For example, one officer stated: 
"I would say that definitely it's upped their numbers of phone calls, that's for sure. There's no downside to that, right? We want those services to be used. It's given them exposure as well. Aside from the fact that they're being used, the community knows about these now. I think that's a huge plus" (Participant 19frontline officer).

Another officer said, "I just feel like the actual places that are getting referred to are actually being utilised... they're [the COAST] able to appropriately refer people to these services, which allow these services that can be used to get proper funding" (Participant 11 - frontline officer).

These views were shared with senior leaders. One participant mentioned, "All of our partners they are now seeing the services being used. And in the past, with the old LHIN system, moving to the health team system, often their systems weren't being used. So, they didn't get the funding anymore. Or, their funding was reduced" (Participant 6- SSPS COAST Supervisor).

In addition to the services being utilized, there were some additional benefits of the COAST for the service providers that are worth noting. COAST members and some senior leaders mentioned that there are instances in which service providers utilize the COAST program to assist with their clients $(n=5)$. For example, there have been instances where case managers request the COAST to attend a well-being check with them for safety reasons, providing a layer of protection for service providers. Lastly, the same participant groups expressed that since the implementation of the COAST, there have been additional resources added to the community $(n$ $=5$ ), such as the addition of a brief services worker (i.e., provides intake, advocacy, referral, and short-term intervention services to individuals with mental health issues) and a police-only crisis bed (i.e., short-term residential crisis support for individuals experiencing mental health symptoms who have made contact with the police). 
Decriminalization. Almost all participants $(n=15)$ said that the implementation of the COAST had resulted in the decriminalization of individuals experiencing mental health related crises. This was commonly associated with the fact that the COAST officer is in plain clothes and the COAST show up in an unmarked vehicle, allowing for more discretion when attending crisis calls. One COAST member stated:

"We're both plainclothes, myself as the officer, with use of force options, but plainclothes, as well as my crisis worker who's a civilian. My crisis response worker trained mental health professional who's also in plainclothes. Which would suggest a decriminalisation, destigmatisation piece when we're there and we're talking with that person, engaging with that person in crisis. That allows, I think, a better relationship to be built in terms of trust, rapport building and more positive outcomes which don't necessarily escalate a person” (Participant 2COAST Officer).

The same participant continued to say, "We're not marked in a vehicle that says police. We're in a minivan, a white, unmarked minivan. The white unmarked minivan is ubiquitous, it's nonconspicuous."

Frontline officers expressed similar views. For example, one officer said: "There are calls where they go to, their follow-ups that they go to, and then the neighbours aren't seeing police at their door day after day after day. And you're not showing up in a police car, right? Neighbours see you go in the back of a police car they automatically think you've done something wrong so I think it kind of eases all of that" (Participant 18- frontline officer).

Another officer stated: 
"The uniform, whether people want to believe it or not, sometimes it's intimidating. With police written everywhere and our belts and everything, I think, plain clothes puts them on the same level. I think people appreciate not having a police cruiser at the front step. Just a regular van or whatever vehicle they're using at the time I think that not all the neighbours are looking out their window" (Participant 14- frontline officer).

Senior leader participants also had a similar perspective. One senior leader said, "The COAST model is plain clothes, plain vehicle. So, removing that criminalisation, that stigma with mental health... It's not police in uniform. And it's not stigmatising. It's decriminalising mental health" (Participant 6- COAST SSPS Supervisor).

Provide better service. Many participants $(n=10)$ touched upon the fact that the COAST is able to provide a better service to individuals experiencing crisis than the traditional police response. Some of the factors that were mentioned included their enhanced level of knowledge and training, as well as having the ability to take the extra time to provide that support to service users as well as responding in an appropriate manner. For example, one COAST member stated:

"We try to support them in the home where they're comfortable. The hospital can be scary. I think that's the long-term goals. And again, we're just trying to make sure people have support and that the first contact isn't with police. That they have a mental health counsellor, worker that can give them that support that they need" (Participant 1- COAST CRW).

Frontline officers also recognized the COAST's ability to handle crisis calls more appropriately. For example, one officer said: 
"Frontline officers, they go to the call, they do the police work and the next day they don't really have the time to do the follow-ups or what's needed to really deal with a mental health-related call. Where COAST, you can take that extra one, two, three hours, whatever it may be, actually deal with that problem" (Participant 12- frontline officer).

Another officer mentioned that, "it allows for people with better knowledge and better training to deal with the calls and make the decisions" (Participant 18-frontline officer).

Senior leaders also expressed similar views. One senior leader stated:

"It's not just about responding after the fact to an event or a crime. Not only does it say we're here to serve and protect, but we have services that provide that support. That is, it is about help and it's about recognising that mental health and addictions is a big challenge for communities. It's understanding that and being responsive, as opposed to just trying to treat every issue with the same using the same technique. It really broadens the support that we can provide to the community" (Participant 7- YSSN Senior Leader).

Another senior leader also said, "So, ideally, the outcome that we're looking for is to provide a better service to those with mental health issues, and that's... Whether that's pre-crisis, postcrisis, or in-crisis care, to get the people the best care that they can be provided" (Participant 4SSPS Chief of Police).

Bridge gap. Some participants $(n=9)$ spoke about how the COAST bridges an existing gap between police and mental health care. The COAST is able to provide supports to individuals in crisis who are coming into contact with the police and are unaware of the resources that are available to them. In addition, the COAST also serves as a support service 
itself due to the lack of resources in the community. For example, one COAST member stated, “The services are lacking in both Bradford and Innisfil. We're filling that service gap, sadly. But nonetheless, it's the reality of our community" (Participant 2- COAST Officer). Another COAST member mentioned, "We're a hub for resource information in the community that we can spread the word because of the apparent lack of accessibility and the visual presence. So we are a conduit, a gateway to support services" (Participant 3- COAST CRW). Another COAST member also said, "COAST bridges that gap and we refer on to other places and we provide that support right away" (Participant 1- COAST CRW).

It was also often noted that the COAST fills a service gap in terms of providing an enhanced response in which frontline officers cannot provide. For example, one frontline officer stated:

"I feel that COAST is trying to bridge the gap for a lot of the things that we lack in either resources or even knowledge. They have a particular specific skillset and knowledge of not only referrals, but the system, how people can be helped, better than a frontline officer. Really, we're limited with what we can do" (Participant 11- frontline officer).

Another officer also said, "I think they're trying to bridge that gap, I would guess and just be there to fill in all those pieces that maybe your frontline officer doesn't know about or isn't directly affiliated with, and maybe isn't specialised in handling those conversations" (Participant 17- frontline officer).

Lastly, senior leaders also noted that the COAST provides service users with immediate support. For example, one senior leader stated: 
"Our health system is overtaxed, so often at the hospital they're not getting connected to resources as fast as they would at the COAST model, right at the root of the call. Often within hours, that person in crisis are now deescalated out of crisis, and already starting to set up appointments with referrals and supports. So, the individual, the person in crisis, gets help immediately" (Participant 6SSPS COAST Supervisor).

\section{COAST Challenges}

Despite the overwhelmingly positive views most participants had regarding the COAST, there were some challenges that were noted. The biggest challenge identified was the lack of coverage that the COAST is able to provide. Other challenges included funding, a lack of awareness of the program, and the need to improve the relationship between the COAST (and SSPS more generally) and the hospitals.

Coverage. Nearly all participants $(n=18)$ expressed concern with the lack of coverage of the COAST program. Most notably, there was frustration among frontline officers about the lack of availability for live crisis calls. The lack of coverage was often associated with limited resources, being that there is only one COAST officer and a few crisis workers. One COAST member stated:

"Major challenges, coverage. Again, it would be fantastic if we could respond to every live call so that somebody... Because even the follow-ups are great that we have them, but that means in that instance, that person did not have a mental health worker to support them through that crisis. If we could go to every live call, the diversions would go up. The trauma that that client had to experience would go down" (Participant 1- COAST CRW). 
Another COAST member said: "If anything, we're a source of disappointment or frustration because we're not working more. They [frontline officers] wish we were at this call or you should have been to this call because we are working or we're busy on another call" (Participant 2- COAST Officer).

This view was consistent with frontline officers. One officer said:

"The biggest challenges is you've got, one officer and he works with a couple of crisis workers, but when he's not there, then we don't have COAST. Then there's stuff piling up that he has to follow-up on when he comes back. If you had one or two, or two or three, at least there's that constant interaction and you are able to use COAST a lot more on your calls" (Participant 15- frontline officer).

Another officer also mentioned, “There's a little bit of animosity because he's not available for most of our calls. A lot of frontline officers don't see it as a beneficial unit only because it's not available to them as it's promoted" (Participant 16- frontline officer). As well, officers often noted the limited COAST schedule as a disadvantage because "Policing is 24 hours, 7 days a week" (Participant 15- frontline officer).

These views were consistent with senior leader participants. For example, one senior leader stated: "When we don't have COAST running, I'm tying up officers that ought not to be tied up. I should have a COAST unit out there responding to that one call on Saturday" (Participant 5- SSPS Deputy Chief). Another senior leader also mentioned "I think the biggest challenge is probably needing more resource for that team. We don't have seven days coverage" (Participant 7- YSSN Senior Leader). 
It is also worth noting that several frontline officers $(n=4)$ mentioned that the large geographical area that SSPS covers also limits the COAST's ability to attend live calls as it can take a considerable amount of time to drive from one jurisdiction to the other.

Funding. As with many programs and services, one of the most commonly noted challenges for the COAST was funding. A number of participants $(n=6)$ mentioned that money was a challenge for the program and was often used to explain the lack of resources for the COAST. One COAST member said:

"Ideally, I would like to see a seven-day and I would like to see a coverage extending into the later evening to night hours for the variety of reasons that I've already mentioned in this interview. And obviously with that, there comes funding. The funding mechanism has to kick in too" (Participant 2- COAST Officer).

Frontline officers also mentioned funding as an issue. For example, one officer mentioned, "I mean financial is a big part of it and that's probably why they don't have more people" (Participant 19- frontline officer).

Senior leaders also shared this sentiment: "We're finding that it works so well, that we really want to move ahead and have seven-day coverage. But our police budgets are budgeted a year in arrears. And like anything, it doesn't account for that major growth" (Participant 6- SSPS COAST Supervisor). Another senior leader said, “It's funding. It's hard to get funding. It's hard for South Simcoe to get funding. It was hard for us" (Participant 7- YSSN Senior Leader), while another senior leader mentioned, "I know they [SSPS] want more service from us. We just don't have the money yet" (Participant 8- CMHA Senior Leader). 
Program awareness. A handful of participants $(n=6)$ discussed the lack of awareness among the general public in regard to the COAST program. This was thought to potentially hinder accessibility to the program. A COAST member stated:

"We'd love to get involved in more. But again, with the program, it is very busy and we are... If a call comes through, we're at the beck and call. We have to go. We absolutely do become involved. Again, it's just showing our presence there. It's a newer program. A lot of people aren't aware of it. And sometimes if you can have a face that people recognise, they're more likely to reach out and ask for our support” (Participant 1- COAST CRW).

Another COAST member said, "The awareness piece needs to increase some way or somehow, particularly with certain audiences that don't even think it's a thing, it's a support" (Participant 2- COAST Officer), while another COAST member mentioned, “I don't think the general public as a generalisation is very aware" (Participant 3- COAST CRW).

Frontline officers also felt that awareness needed improvement:

“I just don't think the majority of the public knows that it even exists and I don't think that there would be a correlation between a police service and a crisis outreach team. I would think that you don't associate the two together... And that's the reaction that I get most often usually from the family of whomever is in crisis. Yes, they don't even know that this is a resource that's available" (Participant 13- frontline officer).

Another officer had a similar perspective: "I don't know that people know about it as much as they could because for sure, sometimes people are surprised. I live in this community and prior to thinking about working here, I didn't know it was a thing" (Participant 17- frontline officer). 
In addition, one senior leader mentioned that there was a lack of understanding of the COAST mandate: "I think it's just familiarity with the program. So, some people will assume they need COAST, but that's because they only understand it to a degree. So, I think it's just a learning curve for everyone. So, sometimes we get referrals that are not appropriate for COAST" (Participant 8- CMHA Senior Leader).

Relationship with hospitals. Some participants $(n=7)$ expressed challenges associated with the partnership between SSPS, the COAST, and the local hospitals. There seems to be a lack of understanding, and perhaps also a lack of respect between the police and the healthcare system. One COAST member stated, "We would like to build better relationships with the hospitals. Which sadly, in our experiences, seem to be very insular still and want to maintain their domain, if you will, of all things mental health" (Participant 2- COAST Officer). When asked about the impact the COAST has had on the hospitals, the same participant said "I can't speak from any other piece because, sadly, our relationship isn't where I would like it to be in terms of our collaborative partnership".

A frontline officer also mentioned, "Some hospital staff I don't think necessarily appreciate or value a police officer's opinion on the matter. And they think we're sometimes just dumping people on them" (Participant 9- frontline officer). Another officer also said:

"I can say a lot of doctors don't want to listen to me. And I can tell you that these are the symptoms, and this is what's going on. And what we're run up with is two, three hours sometimes wait periods where the situation has calmed down, it has diffused greatly. And they're coming in and they're going, really? And they don't see it, and then we're frustrated because I'm like, you don't understand. I've 
waited for three hours. And you're like, hey, bye, looks like you're doing well, see you later" (Participant 17- frontline officer).

Lastly, senior leaders also discussed the challenges in relation to the hospitals:

“They're still of the mindset that there's no reason why cops can't wait more than two hours to have a person in apprehension. They don't see the stigmatisation. They don't see the value of diversion, of being diverted from the emergency room... it's hours before they come and talk to us. So, even when we have a COAST officer there who can articulate, they don't want to talk to us... So, another challenge we're finding is getting our hospital healthcare systems on board" (Participant 6- COAST Supervisor).

Despite the agreement that the partnership with the hospitals requires improvement, some participants did mention that the implementation of COAST had improved the relationship with the hospitals in some capacity. For example, a few participants associated COAST with reduced wait times $(n=3)$. In addition, some frontline officers and senior leaders mentioned the COAST's ability to "speak the same language" as medical professionals $(n=7)$, which was seen as an advantage of the COAST in terms of improving the working relationship between SSPS and the hospitals. Furthermore, both COAST members and senior leaders believed that the COAST helps to reduce the workload of the hospitals due to the increased number of ED diversions $(n=5)$. Lastly, many participants, especially frontline officers, felt that they could not speak to the impact the COAST has had on hospitals $(n=8)$.

\section{Discussion}

Due to the growing number of interactions between the police and persons in crisis, CIT and MCIT programs have become more and more prevalent in hopes to improve the ways in 
which the police respond to calls involving individuals experiencing mental health related crises. Previous research has typically focused on initial quantitative assessments of these specialized programs without any follow-up evaluations and long-term tracking. The current study sought to provide a qualitative assessment of the SSPS COAST, building upon the initial quantitative assessment completed by Semple and colleagues (2020), to examine program fidelity and whether the goals of the program are being met. This evaluation is also intended to inform best practices to improve the ways in which SSPS and their partners provide services to individuals in crisis.

The following discussion provides an overview of the major themes, findings, and implications to emerge from the interviews while also highlighting similar outcomes from previous evaluations of other CIT and MCIT programs. It is important to note that comparisons of these specialized response programs can be challenging as they can vary greatly in terms of populations served, funding levels, program procedures, hours of operations, expertise, and training (Kean et al., 2012; Ligon, 1997; Shapiro et al., 2015). Furthermore, the main objectives and activities among these types of programs can also greatly differ (Patterson, 2010). For example, some programs may focus their efforts on partnership building between the police and the health system, while others may prioritize referrals or personnel training. While some of the findings of the current study are similar to the findings of other evaluations of similar specialized response programs, some of the findings are specific to the SSPS COAST program due to their particular inputs and central activities.

\section{Research Question 1: Why Was the COAST Implemented?}

Overall, there was strong consensus among participants regarding the reasons why the COAST program was implemented. Participants agreed that there was a need for the COAST 
program in South Simcoe due to the increasing numbers of contacts between SSPS and individuals experiencing crises, as well as the growing number of mental health related calls which SSPS receive. The increasing interactions between police and individuals who experience mental health related crises continues to rise across North America (Abbot, 2011; Coleman \& Cotton, 2010; Shapiro et al., 2015). Because of this, police officers are often described as the frontline responders to mental health crises and 24/7 mental health workers (Steadman et al., 2000; Thompson, 2010). This sentiment was shared by participants from the current study. The increase in contact between police and individuals was often attributed by the interviewees to the fact that police are "the only thing that's open 24 hours".

In addition, deinstitutionalization, which has led to individuals with mental health issues now residing in the community as opposed to psychiatric facilities, coupled with reduced funding for supports and resources within the community, has also made it challenging for individuals experiencing mental heath related crises to access adequate treatment, leading to greater contact between police and PMIs (Borum et al., 1998; Cooper et al., 2004 Ruiz \& Miller, 2004). Sadly, this appears to be as true in South Simcoe as it is everywhere else. Indeed, participants in the current study agreed that the lack of sufficient mental health services in the communities of Bradford and Innisfil contributed to the increased contact between police and persons in crisis, leading to a need for the COAST program.

Lastly, participants acknowledged the need for a specialized response to crisis situations in South Simcoe as frontline officers are generally not equipped to appropriately handle persons in crisis. This finding is consistent with other studies where police officers report that they do not feel adequately trained to respond to these types of situations (Borum et al., 1998; Reuland et al., 2009). Furthermore, similar to findings in other evaluations of MCIT programs (e.g., Lamanna et 
al., 2018), participants in the current study touched upon the fact that frontline officers tend to frequently apprehend individuals under the Mental Health Act, which typically does not result in the individual being admitted to the hospital or receiving any further support once the initial crisis has subsided. Frontline officers in South Simcoe felt that they do not possess the expertise needed to de-escalate situations to a point where they feel comfortable letting the individual in crisis go as opposed to apprehending. If individual in crisis are looking to the police for help and officers are unable to respond appropriately, then these individuals will not receive the proper care they need, which may also lead to re-occurring calls for service to the police.

\section{Research Question 2: COAST Operate as Intended?}

In terms of how the COAST operates, most participants touched upon a handful of responsibilities that the COAST is accountable for. These are all responsibilities that the COAST is designed to undertake (see the previously discussed logic model; Figure 1). First, the COAST is responsible for providing formal training to all frontline officers on mental health issues with the intention of improving the ways in which officers respond to individuals in crisis. Most frontline officers I interviewed agreed that the training had improved their abilities and comfortability in handling crisis calls. In addition, the COAST also provides training in regard to the COAST itself (i.e., how the COAST operates) so that officers know how to utilize the COAST and when it is appropriate to do so. That being said, some officers mentioned that they require more clarity with respect to COAST goals and when it is appropriate to utilize the team. To ensure the COAST program is working as efficiently and effectively as possible, it would be beneficial for the COAST (or SSPS leadership) to provide further clarity on appropriate scenarios in which the COAST can be utilized. This may help to avoid situations where the COAST is requested to attend a call, but their services are actually not required, or situations 
where they are not requested, but should be (resulting in people who could have benefited from the COAST being missed).

Second, all participants agreed that the COAST is responsible for connecting service users to appropriate resources within the community. Often, it can be challenging to identify desirable outcomes for individual service users when evaluating these types of programs (Landeen et al., 2004). Although this was not specifically addressed in the current evaluation, it was clear from the interviews I conducted that the COAST had extensive knowledge of their local resources and were able to not only connect service users to these resources but connect them to resources that are relevant and appropriate (e.g., addiction services for people struggling with addiction). By connecting service users to the right resources it provides these individuals with an opportunity for long-term care, which should ultimately help them work towards developing coping mechanisms that will hopefully minimize future calls to the police.

In addition, it was clear from the interview responses that conducting follow-ups with service users was one of the main activities of the COAST. This activity was also seen as one of the most important roles of the COAST. Not only do follow-ups allow the COAST to check in to see how the service user is doing, post-crisis, follow-ups also provide an opportunity for the COAST to discuss the available resources with service users in a calmer setting (the individual is less likely to take that information in or be open to the possibility of seeking help mid-crisis), which may help to reduce further contact with the police (Finn \& Sullivan, 1989; Lamanna et al., 2015).

Furthermore, de-escalation of crisis situations with the goal of emergency department diversion (ED) was described as another important COAST activity. Having the necessary skills to de-escalate individuals in crisis and avoid a potentially lengthy trip to the hospital, where 
service users are unlikely to receive the appropriate care (Lauer \& Brownstein, 2008), was noted as a core function of the COAST. By successfully de-escalating crisis scenarios, this reduces the potential for unnecessary arrests or apprehensions, which were thought to be "band-aid" solutions by the interviewees. Avoiding EDs and connecting service users to resources within the community is considered to be the most appropriate method for supporting most service users and reducing future contact with the police (Finn \& Sullivan, 1989), and the resultant possibility of the user being criminalized (Compton et al., 2008).

Lastly, COAST members and senior leader participants discussed the importance of program monitoring by collecting data regarding the number of crisis calls, referrals, ED diversions, follow-ups, live-call attendance, and so on. Program tracking by SSPS and their partners, and by outside researchers like me, will allow for greater accountability in terms of the identifying areas where the COAST can improve, as well as highlighting program successes to support continued request for funding for the program. The fact that this is being done in South Simcoe is very promising. The police have historically been very good at identifying problems that need to be targeted, and developing strategies to target them, but quite poor at evaluating these strategies, especially over time, to ensure that the strategies actually work as intended and are modified as necessary (Huey et al., 2017).

\section{Research Question 3: What Are the Goals of the COAST and Are They Being Achieved?}

With respect to the goals of the COAST, participants agreed that there were several main objectives, most of which were being achieved. Almost all participants stated that the COAST helps to alleviate frontline officer resources, a finding that is consistent with the previous quantitative evaluation of the COAST in SSPS (Semple et al., 2020). Crisis calls are often described as being very time-consuming as they utilize a significant amount of police resources 
(i.e., ED wait times; Morabito et al., 2012; Thompson, 2010). When the COAST is able to attend a crisis call, it allows frontline officers to attend other calls for service as opposed to spending several hours dealing with the individual in crisis. Previous evaluations have also found a decrease in on-site handling time for frontline officers associated with a co-responding policemental health program (e.g., Shapiro et al., 2015). Freeing up frontline officer resources allows the police to attend to traditional law enforcement activities that actually benefit from a police response, whereas individuals in crisis typically may not benefit from front-line police involvement due to their lack of adequate training and knowledge regarding mental health and relevant community resources (Borum et al., 1998; Lord et al., 2011; Reuland et al., 2009; Ritter et al., 2010). Although many participants acknowledged the advantage of COAST in freeing-up frontline officers, it was frequently mentioned along with the caveat that the lack of COAST resources has hindered their ability to attend live crisis calls. Due to the limited COAST resources, frontline officers are still often managing crisis calls, which ultimately perpetuates a gap in service.

Many participants also discussed that one of the main goals of the COAST is to provide enhanced support to service users and their families. Although service users were not interviewed for the current study, or examined in the previous evaluation of the SPSS COAST (Semple et al., 2020), several participants provided anecdotes about instances where they received positive feedback from a service user or their family member about their experience with the COAST, often mentioning that they felt supported and validated. Another study in which service users were interviewed found that these individuals valued the knowledge of the responding MCIT regarding mental health, as well as their compassionate and non-criminalizing approach (Lamanna et al., 2018). If the COAST is able to provide a better service to persons in 
crisis, it may increase the likelihood of these individuals receiving appropriate care within their community and subsequently reducing any future need for police involvement. Determining if the SSPS COAST actually provides this better service will be a critical question addressed in the next stage of this research when service users and their families will be interviewed.

Providing enhanced support to individuals in crisis also promotes the goal of reducing the recidivism rate. Since the implementation of the COAST, some participants stated that SSPS is receiving less re-occurring calls from the same individuals. This reduction in recidivism was typically associated with the follow-ups and resource referrals that the COAST provides. A reduction in recidivism may indicate that individuals experiencing mental health related crises are now receiving the necessary care and support via an appropriate service provider in the community and no longer require police intervention. Again, future studies focusing on service users and their families will be needed to confirm that this is what's happening.

Another goal of the COAST is to increase frontline officers' skills and abilities in handling crisis calls, as well as increasing officer knowledge of the support resources available within the community and mental health more generally. The goal of improving frontline officers' skills and knowledge is consistent with other CIT and MCIT programs (Cross et al., 2014; Compton et al., 2008), as is the goal of becoming more informed about their community's mental health services and resources (Shapiro et al., 2015). It appears that these things are happening in South Simcoe. Overall, SSPS frontline officers felt that their abilities with respect to managing crisis calls had improved since the implementation of the COAST. Most officers also felt that they were now more knowledgeable of their local resources, although some officers felt they needed further clarity about the available resources in the community and that generally there could be more training provided. Considering the COAST is not always available to 
respond to live crisis calls, it is important for frontline officers to have this knowledge. Additional formal training for all frontline officers should be considered to ensure an effective and appropriate response to persons in crisis when the COAST is unable to respond.

Historically, there has been an existing gap between police and mental health service providers, often working in silos as opposed to working collaboratively (Lamb et al., 2002). The final goal of the COAST that was mentioned by interviewees was to build a better working relationship between SSPS and the local mental health service providers. COAST members and SSPS, YSSN, and CMHA senior leaders agreed that the COAST has improved the partnership between police and mental health providers. Overall, participants felt that because of the COAST, police and mental health providers now had a better understanding of one another's goals and objectives and that both entities were now able to provide a better, more collaborative service to people in crisis within their community. Although police are often required to respond to individual experiencing mental health related crisis (e.g., in order to ensure their safety and the safety of those around them), the COAST program provides an avenue for mental health experts to reach these individuals and ensure that they are receiving the appropriate care without being criminalized. In addition, the goal of improving partnerships also included the working relationship between the COAST, SSPS, and the local hospitals. Unfortunately, COAST members and SSPS senior leader participants agreed that their relationship with the hospital requires improvement. The challenges associated with the hospitals are discussed in Research Questions 5.

\section{Research Question 4: What Benefits Are Associated With the COAST?}

Despite the identified challenges associated with the COAST program, as discussed below, most participants agreed that the perceived benefits of the COAST outweighed the 
challenges. Nearly all participants discussed the benefit of the COAST in terms of the extra layer of support it provides to frontline officers. For example, many frontline officers explicitly stated that even if the COAST was unable to attend a call, they were able to call the COAST to discuss an appropriate course of action or obtain resource information. This has also been reported in evaluations conducted in other jurisdictions (Lamanna et al., 2015).

Participants also acknowledged the advantage of the partnership between police and mental health experts, specifically the benefit of having a crisis response worker attending crisis calls. Indeed, the COAST's ability to provide a service beyond the traditional police response was often attributed to the presence of a crisis response worker who has extensive knowledge, training, and expertise. The underlying theory of the co-responding model is that the collaboration between the two systems (i.e., police and mental health) provides a better, more effective service to individuals in the community (Rosenbaum, 2010). Based on this ideology, its not surprising that SSPS participants saw great value in having the crisis response workers available to assist in the handling of crisis calls, allowing for an enhanced level of support for service users.

Other perceived benefits associated with the COAST in South Simcoe included the increased utilization of the mental health resources and services in the community, which decreases the existing gap between police and mental health care. Kisely and colleagues (2010) also found an increase in usage of community-based services associated with the co-responding model they evaluated. This benefit of the COAST is especially important because connecting service users with existing community resources is thought to be the most appropriate response to most personal crises and because it contributes to reduced recidivism (Finn \& Sullivan, 1989). Senior leaders of the participating mental health agencies also expressed that having the COAST 
officer provides a level of safety for the crisis response workers and allows the mental health experts to reach individuals who may not have been accessible otherwise. Furthermore, the COAST provides immediate support to individuals in crisis by bringing the service (i.e., a mental health expert) to the individual, as opposed to the individual having to seek out and access the service.

Lastly, the majority of participants mentioned that the COAST decriminalizes mental health. This was often associated with the utilization of a plain clothed police officer and mental health worker, and unmarked vehicle, which allows for discretion when handling crisis calls. Other research has shown that service users feel that the presence of multiple police officers and marked police vehicles criminalizes them (Lamanna et al., 2018). Shapiro and colleagues (2015) also found that several co-responding police-mental health programs supported the decriminalization of mental health via a decrease in service user arrests; something that was found in the previous evaluation of the COAST in South Simcoe. The decriminalization of mental health is not only beneficial for the individual, but also for the police and criminal justice system (CJS). Redirecting individuals experiencing mental health related crises to the available resources and services within the community will allow the individual to receive appropriate care while also alleviating some of the pressure on the CJS by reducing unnecessary incarceration.

\section{Research Question 5: What Challenges Are Associated With the COAST?}

Finally, there were a few challenges associated with the COAST that were consistently mentioned in relation to coverage and resources. Almost all participants had expressed concerns with the lack of coverage of the COAST program, most notably that the COAST is often unavailable to attend live crisis calls. Kisely and colleagues (2010) reported a similar finding when assessing a MHMCT in Nova Scotia, noting that non-MHMCT officers expressed a lack of 
availability of MHMCT staff to respond to crisis calls. Other evaluations of co-responding police-mental health programs also found delayed response times for attending live calls due to the availability issues, lack of staffing, and geographical challenges (Borum et al., 1998; Lamanna et al., 2015; Ratansi, 2004; Steadman et al., 2000). While availability and staffing are a real issue in South Simcoe, geographical challenges are also particularly problematic due to the very large jurisdiction that the SSPS COAST must cover. For example, if the COAST is in Innisfil and there is a crisis call in Bradford, it can take 30 minutes or more for the COAST to arrive on scene. If the COAST is unable to attend live crisis calls, there may be individuals that are neglected who would benefit from an interaction with the COAST. In addition, if frontline officers are left to respond to crisis calls without COAST assistance, it may further contribute to unnecessary apprehensions or arrests (Semple et al., 2020).

Several frontline officers also stated that even though the COAST is not always on duty, many officers are able to contact the COAST officer while he is off duty for advice or information. While this was generally mentioned in a positive light, it could have a potential burn-out effect on the COAST officer. Indeed, research has clearly shown that such off-duty work is a major driver of stress among police officers (Duxbury \& Higgins, 2012). Although there are a few back-up COAST officers in the SSPS, it was clear from the interviews that their knowledge and expertise were not nearly as extensive as that of the main COAST officer. It would be highly beneficial for SSPS to have several COAST officers with equal knowledge, training, and expertise. The challenge of coverage and resources was often attributed to the lack of consistent funding for the COAST program. All senior leader participants stated that ideally the COAST program would run seven days a week and would include more COAST officers and crisis response workers, however all parties (SSPS, YSSN, and CMHA) lack the appropriate 
funding. Hopefully, evaluations like this one, and the one conducted by Semple et al. (2020), will help these organizations secure the extra funding they need.

Other challenges identified included the need to improve the relationship between SSPS, the COAST, and the local hospitals. One of the on-going challenges with respect to crisis calls is the extensive wait-times at the emergency department when an apprehension occurs, which takes up a substantial amount of police resources and often causes frustration among officers (Morabito at al., 2012; Thompson, 2010). A few participants mentioned a reduction in hospital wait-times since the implementation of COAST, however most participants stated that hospital wait times were still considerable. Due to these extensive wait-times, some hospitals in Ontario have arranged agreements with their local police services in an attempt to reduce apprehension wait-times (PHSJCC, 2011). Such an effort would be worthwhile in South Simcoe. However, this will likely require stronger relationships to be developed between SSPS, the COAST, and the local hospitals, something that senior leaders from SSPS and its mental health partners are keen to work on.

Finally, a few participants noted that although the COAST attempts to conduct or participate in community engagement events, there seems to be a lack of program awareness among the general public. Due to the lack of resources available for the COAST, attending live crisis calls and conducting follow ups with service users takes precedence, leaving little time for engagement events. If members of the community are unaware that this service is available, it may inhibit accessibility to the COAST for individuals who may benefit from the program. Given this, there may be some value in exploring resource efficient methods for educating the public (i.e., approaches that don't rely extensively on the COAST team, such as the use of public education videos that can be accessed through the SSPS, CMHA, and YSSN websites). 


\section{Limitations and Future Research}

This project provides an in-depth assessment of the need for the COAST in South Simcoe, the activities and goals of the COAST, and the benefits and challenges of the COAST from various stakeholder perspectives. While this project presents a relatively comprehensive evaluation of program fidelity, it is not without limitations. Perhaps most obvious is the fact that the current evaluation does not include any voices from service users (or their families). Data collection related to user satisfaction is particularly important and very few evaluations of these specialized response programs have focused on user outcomes due to a range of challenges (e.g., gaining access to users who are willing to speak about their experiences; Landeen et al., 2004). Although some interviewees in the current study recounted interactions with service users - all of whom expressed a positive experience with the COAST program - these anecdotes can't take the place of service user accounts. Future evaluations need to consider the inclusion of service users; something that we are planning as the next phase of the evaluation in South Simcoe.

Additionally, one of the goals of the COAST program is to build stronger relationships between SSPS and the local hospitals, but due to time limitations that stakeholder group was also not included in the current study. While some participants were able to speak to this issue, most participants did not have the knowledge to comment on this particular goal. What I could glean from the interviews is that there are some conflicts between the SSPS and the local hospitals (e.g., regarding excessive wait times in the emergency department and how apprehensions should be managed). Given the importance of this relationship to the success of the COAST, and policing in South Simcoe more generally, future evaluations of the COAST program should explore the views of hospital staff to determine how the SSPS, CMHA, YSSN, and the local hospitals can work more collaboratively with one another. 
Furthermore, because of the nature of the participant groups, and the limited number of possible participants, confidentiality may not have been possible to maintain within, and in some cases across, the organizations involved in the study. Participants were made aware of the issues regarding confidentiality in the consent form and by the researcher prior to the commencement of each interview. Although none of the participants seemed concerned about confidentiality, this may have caused some reluctance to speak freely about their thoughts and opinions regarding the COAST. That being said, participants did speak on some of the negative aspects associated with the COAST, therefore it seems unlikely that the lack of confidentiality had an effect on the findings. Nonetheless, it is worth mentioning.

Lastly, it is important to recognize that the participants I interviewed may potentially be biased with respect to these types of specialized response programs. A degree of self-selection may have occurred, whereby officers with positive views towards the COAST may have been more likely to participate in the study. In addition, the nature of the SSPS may have influenced the results. For example, during the interviews, some participants suggested that COAST's ability to provide training to all frontline officers, both formally and informally, could be attributed to the fact that SSPS is a very small police service. This could mean that some of the benefits of the COAST that were highlighted in the current interviews may be specific to this particular program, and the same benefits may not be found if such a program was implemented in a much larger police service. Relatedly, the SSPS COAST has certain qualities, such as funding levels, program procedures, hours of operation, expertise, and training, that can make comparative evaluations of these programs quite challenging. Therefore, the extent to which the findings in my study transfer to other specialized response programs in Canada and elsewhere cannot be determined. 


\section{Conclusion}

Overall, it appears that the COAST in South Simcoe is, for the most part, operating as intended and achieving their goals of supporting service users and their families, freeing up frontline officers to carry out more traditional policing tasks, and building a better relationship between SSPS and local mental health agencies. However, because of the lack of consistent funding, resources and coverage are often insufficient, which hinders the COAST's ability to attend live crisis calls. Frontline officers who are not equipped to appropriately handle crises, despite the training that has been provided, are often left to manage these crisis calls. Although the COAST does provide training to all frontline officers, it was clear that additional training is required as not all officers are confident in their ability to handle crisis situations. This ultimately may mean that there is still some existing gap in service as some individuals who might benefit from an interaction with COAST may be neglected.

In todays climate, social justice movements such as Black Lives Matter have been gaining momentum in their calls to defund the police. Largely, these calls are based on concerns over the increasing number of tragic incidents involving police officers and individuals in crisis. Unfortunately, community mental health resources in general are lacking, and legislation requires that police officers attend mental health calls (e.g., police officers are the only ones that can apprehend people under the Mental Health Act). Thus, currently at least, the reality is that the police are often going to be the ones responding to individuals experiencing crises. Innovative co-responding programs, such as the SSPS COAST, are a step in the right direction towards providing a more appropriate response to those in the community who are dealing with mental health related issues or crises. 
However, the positive impact of these types of programs will be limited if they cannot operate in the way they were intended to operate (e.g., by being able to attend live crisis calls when there is a perceived need by responding frontline officers). Generally, there seems to be a lack of consistent funding for these types of programs, which hinders their potential for success. It is my hope that evaluations of these specialized response programs, like the one reported here, will help them gain the recognition they deserve. With such evaluations in hand, and drawing on the strong relationships that these programs help build between stakeholders, senior leaders in the policing and mental health sector will hopefully be able to make the necessary arguments to secure additional funding for these programs so that they can provide adequate support to the individuals they serve. 


\section{References}

Abbott, S.E. (2011). Evaluating the impact of a jail diversion program on police officer's attitudes toward the mentally ill (Publication No. 3450400) [Doctoral dissertation, Northeastern University]. ProQuest Dissertations \& Theses.

Abram, K. M. (1990). The problem of co-occurring disorders among jail detainees: Anti-social Disorder, alcoholism, drug abuse, and depression. Law and Human Behaviour, 14, 333345. https://doi.org/10.1007/BF01068160

Akland, G., \& Akland, A. (2008). Indicators of the impact of North Carolina's "Mental Health Reform" on people with severe mental illness. National Alliance on Mental Illness, Wake County, NC.

Anney, V., N. (2014). Ensuring the quality of the findings of qualitative research: Looking at trustworthiness criteria. Journal of Emerging Trends in Educational Research and Policy Studies, 5(2), 272-281.

Baess, E. P. (2005). Integrated mobile crisis response team (IMCRT): Review of pairing police with mental health outreach services. $\underline{\text { http://citeseerx.ist.psu.edu/viewdoc/download?doi }=10.1 .1 .583 .1431 \& r e p=r e p 1 \& t y p e=p}$ $\underline{\mathrm{df}}$

Bitsch, V. (2005). Qualitative research: A grounded theory example and evaluation criteria. Journal of Agribusiness, 23(1), 75-91.

Borum, R., Swanson, J. W., Swartz, M. S., \& Hiday, V. A. (1997). Substance abuse, violent Behaviour and police encounters among persons with severe mental disorder. Journal of Contemporary Criminal Justice, 13, 236-250.

https://doi.org/10.1177/1043986297013003004 
Borum, R. (2000). Improving high risk encounters between people with mental illness and the police. Journal of the American Academy of Psychiatry and the Law, 28, 332-337.

Borum, R., Williams Deane, M., Steadman, H. J., \& Morrissey, J. (1998). Police perspectives on responding to mentally ill people in crisis: perceptions of program effectiveness. Behavioral Sciences \& the Law, 16(4), 393-405. https://doi.org/10.1002/(SICI)10990798(199823)16:4<393::AID-BSL317>3.0.CO;2-4

Bowen, G. A. (2009). Supporting a grounded theory with an audit trail: An illustration. International Journal of Social Research Methodology, 12(4), 305-316. https://doi.org/10.1080/13645570802156196

Braun, V., \& Clarke, V. (2006). Using thematic analysis in psychology. Qualitative Research in Psychology, 3(2), 77-101. https://doi.org/10.1191/1478088706qp063oa

Canadian Centre of Public Safety Excellence (n.d.). Police Science (Cadet). https://ccpse.ca/programs/police-science-cadet/

Clarke, V., \& Braun, V. (2017). Thematic analysis. The Journal of Positive Psychology, 12(3), 297-298. https://doi.org/10.1080/17439760.2016.1262613

Coleman, T. G., \& Cotton, D. (2010). Police interactions with persons with a mental illness: Police learning environment of contemporary policing. https://www.mentalhealthcommission.ca/sites/default/files/Law_Police_Interactions_M ental Illness Report ENG 0 1.pdf

Compton, M. T., Bahora, M., Watson, A. C., \& Oliva, J, R. (2008). A comprehensive review of extant research in crisis intervention team (CIT) programs. The Journal of the American Academy of Psychiatry and the Law, 6(1), 47-55.

Compton, M. T., Broussard, B., Hankerson-Dyson, D., Husbands, L., Krishan, S., Stewart-Hutto, 
T., D’Orio, B. M., Olivia, J. R., Thompson, N. J., \& Watson, A. C. (2014). The policebased crisis intervention team (CIT) model: Effects on officers' knowledge, attitudes, and skills. Psychiatric Services, 65(4), 517-522.

https://doi.org/10.1176/appi.ps.201300107

Cooper, V. G., McLearen, A. M., \& Zapf, P. A. (2004). Dispositional decisions with the mentally ill: Police perceptions and characteristics. Police Quarterly, 7(3), 295-310. https://doi.org/10.1177/1098611104267733

Cordner, G. (2006). People with mental illness. https://cops.usdoj.gov/RIC/Publications/copsp103-pub.pdf

Cotton, D., \& Coleman, T. G. (2008). A Study of Police Academy Training and Education for New Police Officers Related to Working with People with Mental Illness. http://www.pmhl.ca/webpages/reports/AApoliceacademy.pdf

Cross, A. B., Mulvey, E. P., Schubert, C. A., Griffin, P. A., Filone, S., Winckworth-Prejsnar, K., DeMatteo, D., \& Heilbrun, K. (2014). An agenda for advancing research on crisis intervention teams for mental health emergencies. Psychiratric Services, 65(4), 530536. https://doi.org/10.1176/appi.ps.201200566

Deane, M. W., Steadman, H. J., Borum, R., Versey, B. M., \& Morrissey, J. P. (1999). Emerging Partnerships between mental health and law enforcement. Psychiatric Services, 50(1), 99-101. https://doi.org/10.1176/ps.50.1.99

Duxbury, L. \& Higgin, C. (2012). Caring for and about those who serve: Work-life conflict and employee well-being within Canada's police departments. https://sprott.carleton.ca/wp-content/uploads/Duxbury-HigginsPolice2012 fullreport.pdf 
Finn, P., \& Sullivan, M. (1989). Police handling of the mentally ill: Sharing responsibility with the mental health system. Journal of Criminal Justice, 17, 1-14. https://doi.org/10.1016/0047-2352(89)90062-7

Fisher, W. H., Geller, J. L., \& Wirth-Cauchon, J. (1990). Empirically assessing the impact of mobile crisis capacity on state hospital admissions. Community Mental Health, 26(3), 245-253. https://doi.org/10.1007/BF00752775

Hall, N., \& Weaver, C. (2008) Submission to the Braidwood Inquiry into the use of tasers: A perspective from the Canadian Mental Health Association BC Division. https://cmha.bc.ca/wp-content/uploads/2016/07/Braidwood_Inquiry Submission5.pdf

Hanafi, S., Bahora, M., Demir, B. N., \& Compton, M. T. (2008). Incorporating crisis intervention team (CIT) knowledge and skills into the daily work of police officers: A focus group study. Community Mental Health Journal, 44, 427-432. https://doi.org10.1007/s10597-008-9145-8

Huey, L., Blaskovits, B., Bennell, C., Jawaid, K., \& Walker, T. (2017). To what extent do Canadian police professionals believe that their agencies are 'Targeting, Testing, and Tracking' new policing strategies and programs?, Police Practice and Research, 18(6), 544-555. https://doi.org/10.1080/15614263.2017.1363968

Kean, R., Bornstein, S., \& Mackey, S. (2012). Mobile mental health crisis intervention in the Western Health Region of Newfoundland and Labrador. www.nlcahr.mun.ca/CHRSP/RER MH Crisis Intervention.pdf

King, N. (2004). Using templates in the thematic analysis of text. In Cassell, C., \& Symon, G. (Eds.), Essential guide to qualitative methods in organizational research (pp. 257-270). Sage. 
Kirst, M., Pridham, K. F., Narrandes, R., Matheson, F., Young, L., Niedra, K., \& Stergiopolous, V. (2015). Examining implementation of mobile, police-mental health crisis intervention teams in a large urban center. Journal of Mental Health, 24(6), 369-374. https://doi.org/10.3109/09638237.2015.1036970

Kisely, S., Campbell, L. A., Peddle, S., Hare, S., Pyche, M., Spicer, D., \& Moore, B. (2010). A Controlled before-and-after evaluation of a mobile crisis partnership between mental health and police services in Nova Scotia. The Canadian Journal of Psychiatry, 55(10), 662-668. https://doi.org/10.1177/070674371005501005

Lamanna, D., Kirst, M., Shapiro, G. K., Matheson, F. I., Nakhost, A., \& Stergiopoulos, V. (2015). Toronto Mobile Crisis Intervention Team (MCIT): Outcome Evaluation Report. http://stmichaelshospitalresearch.ca/wp-content/uploads/2016/12/MCIT-outcomeevaluation-Final-report.pdf

Lamanna, D., Shapiro, G. K., Kirst, M., Matheson, F. I., Nakhost, A., \& Stergiopoulos, V. (2018). Co-responding police-mental health programmes: Service user experiences and outcomes in a large urban centre. International Journal of Mental Health Nursing, 27, 891-900. https://doi.org/10.1111/inm.12384

Lamb, H. R., Weinberger, L. E., \& DeCuir, W. J, Jr. (2002). The police and mental health. Psychiatric Services, 53(10), 1266-1271. https://doi.org/10.1176/appi.ps.53.10.1266

Landeen, J., Pawlick, J., Rolfe, S., Cottee, I., \& Holmes, M. (2004). Delineating the population served by a mobile crisis team: Organizing Diversity. The Canadian Journal of Psychiatry, 49(1), 45-50. https://doi.org/10.1177/070674370404900107

Lauer, M., \& Brownstein, R. (2008). Replacing the revolving door: A collaborative approach to 
treating individuals in crisis. Journal of Psychosocial Nursing and Mental Health Services, 46(6), 25-33.

Li, D. (2004). Trustworthiness of think-aloud protocols in the study of translation processes. International Journal of Applied Linguistics, 14(3), 301-313. https://doi.org/ $\underline{10.1111 / j .1473-4192.2004 .00067 . x}$

Ligon, J. (1997). Crisis psychiatric and substance abuse services: Evaluation of a community program in an urban setting. (Publication No. 304353794) [Doctoral dissertation, University of Georgia]. ProQuest Dissertations \& Theses Global.

Lincoln, Y. S., \& Guba, E. G. (1985). Naturalistic Inquiry. Sage Publications.

Livingston, J. D. (2016). Contact between police and people with mental disorders: A review of rates. Psychiatric Services, 67(8) 850-857. https://doi.org/10.1176/appi.ps.201500312

Lord, V. B., Bjerregaard, B., Blevins, K. R., \& Whisman, H. (2011). Factors influencing the responses of crisis intervention team-certified law enforcement officers. Police Quarterly, 14(4), 388-406. https://doi.org/10.1177/1098611111423743.

Morabito, M. S., Kerr, A. N., Watson, A., Draine, J., Ottati, V., Angell, B. (2012). Crisis Intervention teams and people with mental illness: Exploring factors that influence the use of force. Crime \& Delinquency, 58(1), 57-77. https://doi.org/10.1177/0011128710372456

Patterson, G. T. (2010). Police-social work crisis teams: Practice and research implications. Stress, Trauma, and Crisis: An International Journal, 7, 93-104. https://doi.org/10.1080/15434610490450886

Perkins, E., Cordner, G., \& Scarborough, K. (1999). Police handling of people with mental 
illness. In G. Gaines \& G. Cordner (Eds.), Policing perspectives: An anthology. Roxbury.

Pizzingrilli, B., Hoffman, R., \& Hirdes, D. P. (2015). A protocol to reduce police wait times in the emergency department. Healthcare Management Forum, 28(4), 134-138. https://doi.org/10.1177/0840470415581257

Provincial Human Services and Justice Coordinating Committee (2011). Police and mental health: A critical review of joint police/mental health collaborations in Ontario. http://www.hsjcc.on.ca/Provincial/Police\%20and\%20Mental\% 20Health\%20Project/Police\%20and\%20Mental\%20Health\%20\%20A $\% 20$ Critical $\% 20$ Review $\% 20$ of $\% 20$ Joint $\% 20$ Police-Mental $\%$ 20Health\%20Collaborations\%20in\%200ntario.pdf

Ratansi, S. (2004). Specialized response programs: Police handling of encounters involving persons with mental disorders. (Publication No. 3182156) [Doctoral Dissertation, University of Cincinnati]. ProQuest Dissertations \& Theses Global.

Rosenbaum, N. (2010). Street-level psychiatry-a psychiatrist's role with the Albuquerque police department's crisis outreach and support team. Journal of Police Crisis Negotiations, 10(1), 175-181. https://doi.org/10.1080/15332581003757040

Royal Canadian Mounted Police (May 1, 2018). Responding to people in crisis. http://www.rcmp-grc.gc.ca/en/responding-people-crisis

Reuland, M., Schwarzfeld, M., \& Draper, L. (2009). Law enforcement responses to people with mental illness: A guide to research-informed policy and practice. https://www.nccpsafety.org/assets/files/library/LE_Responses to Mental_Illnesses_Policy_and_Practice.pdf 
Ritchie, J., Lewis, J., Elam, G., Tennant, R., \& Rahim, N. (2014). Designing and selecting sample sizes. In J. Ritchie, J. Lewis, C. McNaughton Nicholls, \& R. Ormston (Eds.), Qualitative research practice: A guide for social science students \& researchers $\left(2^{\text {nd }}\right.$ ed., pp. 111-146). Sage.

Ritter, C., Tellet, J. L. S., Munetz, M. R., \& Bonfine, N. (2010). Crisis intervention team (CIT) Training: Selection effects and long-term changes in perceptions of mental illness and community preparedness. Journal of Police Crisis Negotiations, 10(1-2), 133-152. https://doi.org/10.1080/15332581003756992

Ruiz, J., \& Miller, C. (2004). An exploratory study of Pennsylvania police officers' perceptions of dangerousness and their ability to manage persons with mental illness. Police Quarterly, 7(3), 359-371. https://doi.org/10.1177/1098611103258957

Schutt, R. K. (2006). Investigating the social world: The process and practice of research (5 ed.). Pine Forge.

Sealy, P., \& Whitehead, P. C. (2004). Forty years of deinstitutionalization of psychiatric services in Canada: An empirical assessment. The Canadian Journal of Psychiatry, 49(4), 249257. https://doi.org/10.1177/070674370404900405

Semple, T., Tomlin, M., Bennell, C., \& Jenkins, B. (2020). An evaluation of a community-based joint mobile crisis intervention team in a small Canadian police service. Community Mental Health Journal. https://doi.org/10.1007/s10597-020-00683-8.

Shapiro, G. K., Cusi, A., Kirst, M., O’Campo, P., Nakhost, A., \& Stergiopoulos, V. (2015). CoResponding police-mental health programs: A review. Adm Policy Ment Health, 42, 606-620. https://doi.org/10.1007/s10488-014-0594-9

Sharma, M., \& Bennett, R. (2015). Substance abuse and mental illness: Challenges for 
interventions. Journal of Alcohol \& Drug Education, 59(2), 3-6.

Sherman, L. (2013). The rise of evidence-based policing: Targeting, testing, and tracking. Crime and Justice, 42, 377-451. https://doi.org/10.1086/670819

Steadman, H. J., Deane, M W., Borum, R., \& Morrissey, J. P. (2000). Comparing outcomes of major models of police responses to mental health emergencies. Psychiatric Services, 51(5), 645-649. https://doi.org/10.1176/appi.ps.51.5.645

Stefan, S. (1996). Issues relating to women and ethnic minorities in mental health treatment and law. In B.D. Sales \& D. W. Shuman (Eds.), Law, mental health, and mental disorder (pp. 240-278). Brooks/Cole.

Swartz, M. S., Swanson, J. W., Hiday, V. A., Borum, R., Wagner, H. R., \& Burns, B. J. (1998a). Violence and severe mental illness: the effects of substance abuse and nonadherence to medication. Am J Psychiatry 155, 226-231. https://doi.org/10.1176/ajp.155.2.226.

Swartz, M. S., Swanson, J. W., Hiday, V. A., Borum, R., Wagner, H. R., \& Burns, B. J. (1998b). Taking the wrong drugs: The role of substance abuse and medication non-compliance among severely mentally ill individuals. Social Psychiatry and Psychiatric Epidemiology, 33, S75-S80.

Taheri, S. A. (2016). Do Crisis Intervention Teams reduce arrests and improve officer safety? A systematic review and meta-analysis. Criminal Justice Policy Review, 27(1), 76-96. https://doi.org/10.1177/0887403414556289.

Teddlie, C., \& Yu, F. (2007). Mixed methods sampling. Journal of Mixed Methods Research, 1(1), 77-100. https://doi.org/10.1177/2345678906292430.

Thompson, S. (2010). Policing Vancouver's mentally ill: The disturbing truth beyond lost in 
transition. https://vancouver.ca/police/assets/pdf/reports.../vpd-lost-in-transition-part-2draft.pdf

Tobin, G. A., \& Begley, C. M. (2004). Methodological rigour within a qualitative framework. Journal of Advanced Nursing, 48(4), 388-396. https://doi.org/10.1111/j.1365$\underline{2648.2004 .03207 . x}$

Watson, A. C., \& Fulambarker, A. J. (2012). The crisis intervention team model of police response to mental health crises: A primer for mental health practitioners. Best Practices Mental Health, 8(2), 71-81.

Wolff, N. (1998). Interactions between mental health and law enforcement systems: Problems and prospects for cooperation. Journal of Health Politics and Law, 23(1), 133-174. https://doi.org/10.1215/03616878-23-1-133

Wood, J., Swanson, J., Burris, S., \& Gilbert, A. (2011). Police interventions with persons affected by mental illnesses: A critical review of global thinking and practice. http://publichealthlawresearch.org/product/police-interventions-persons-affected$\underline{\text { mental-illnesses }}$ 


\section{Appendix A}

\section{Interview Questions: COAST Team Members}

1. Who are the first responders for people experiencing mental health crises in your community?

2. Are community mental health resources in South Simcoe sufficient and accessible by service users? If not, what problems does this cause?

3. Are front-line officers in South Simcoe well-equipped to deal with these situations? Why or why not?

4. Is there a need for COAST in South Simcoe? Why or why not?

5. What are the goals of COAST? [If not mentioned, ask about short, medium, and longterm goals in logic model to confirm whether they are in fact goals or not.]

a. Are these goals being achieved? What aspects of COAST are most important in allowing the program to achieve its goals?

b. For goals that aren't being achieved, why are they not being achieved? What do you think needs to be put into place?

6. I'd like to learn more about specific aspects of COAST, and if/how/why these aspects of the program are important (for the SSPS and its officers, for your mental health partners, for the community at large, and for service users and their families):

a. Does COAST adopt a co-responding approach? Is the co-responding approach important? What does this accomplish?

b. Does COAST conduct routine follow-ups with service users? Are routine followups important? What do they accomplish?

c. Does COAST provide information sessions to SSPS front-line officers? Are information sessions to SSPS front-line officers important? What do they accomplish?

d. Does COAST get involved in community engagement events? Are community engagement activities important? What do they accomplish?

e. Does COAST provide referrals to community services? Are referrals to community services important? What do they accomplish?

f. Does COAST evaluate the program? How? Is this important? What does this accomplish?

g. Are there other aspects of COAST (and their impact) that we have not asked about?

7. Do you think that COAST has had an impact (positive and/or negative) on the following groups:

a. Service users and their families

b. Front-line officers

c. Hospital staff

d. Mental health service providers

e. The community more generally

8. Are there any major challenges with COAST as it currently operates? If so, what are they? What do you think are the most important aspects of the COAST program that helps meet the needs of the community? Is there room for improvement?

9. Is there anything that you would like to add that we have not asked you about? 


\section{Appendix B}

\section{Interview Questions: Frontline Officers}

1. How long have you been working with South Simcoe Police Service?

a. What is your role within SSPS?

2. Who are the first responders for people experiencing mental health crises in your community?

3. Are front-line officers in South Simcoe well-equipped to deal with these situations? Why or why not?

4. What exposure do you have to COAST?

a. Is it a service that you use frequently?

b. Do you think it is an effective service? Why or why not?

5. Is there a need for COAST in South Simcoe? Why or why not?

6. What is the nature of the relationship between COAST and front-line officers in SSPS?

a. What triggers a call to COAST?

b. What roles do front-line officers and COAST play when crisis calls occur?

7. What is COAST trying to accomplish? [If not mentioned, ask about short, medium, and long-term goals in logic model to confirm whether they are in fact goals or not.]

8. Are these goals being achieved? For goals that aren't being achieved, why are they not being achieved?

9. What aspects of COAST are most important in allowing these goals to be achieved?

10. What impact (positive and/or negative) has COAST had on the following groups:

a. Service users and their families

b. Front-line officers

c. Hospital staff

d. Mental health service providers

e. The community more generally

11. Following up on the impact that COAST had on front-line officers, has COAST impacted:

a. Your attitudes and knowledge of people experiencing mental illnesses? If so, in what ways?

b. Your knowledge of mental health resources in the community? If so, in what ways?

c. Your ability to more effectively handle mental health calls? If so, in what ways?

d. Are there any other impacts that COAST has had on you or your front-line officer colleagues?

12. From the perspective of a front-line officer, are there any major challenges with COAST as it currently operates? If so, what are they? Are there certain aspects that you think are particularly important?

13. Is there anything that you would like to add that we have not asked you about? 


\section{Appendix C}

\section{Interview Questions: Senior Leaders}

1. When was COAST implemented?

2. Why was COAST implemented?

3. How is the program currently funded?

4. What contributions to the program are made by SSPS, CMHA, and YSSN?

5. How has the program impacted the partnership between SSPS, CMHA, and YSSN?

6. From your perspective, what are the major goals of COAST?

7. Do you believe that these goals are being achieved?

8. What impact (positive and/or negative) has COAST had on the following groups:

a. Service users and their families

b. Front-line officers

c. Hospital staff

d. Mental health service providers

e. The community more generally

f. Are there any other impacts that COAST has had that we have not discussed?

9. Do you see value in the sorts of program evaluations that we're conducting? What do you hope to accomplish through these evaluations?

10. Are there any major challenges with COAST as it currently operates? If so, what are they? Are there certain aspects that you think are particularly important?

11. Is there anything that you would like to add that we have not asked you about? 


\section{Appendix D}

\section{Recruitment Email}

Subject: Invitation to participate in a research project on the South Simcoe Police Service's Crisis Outreach and Support Team

Dear Sir or Madam,

My name is Jamie Thompson and I am a master's student in the Psychology Department at Carleton University. I am working on a research project under the supervision of Professor Craig Bennell.

I am writing to you today to invite you to participate in a study entitled "A qualitative evaluation of a co-responding mobile crisis intervention team in a small Canadian police service". This study aims to evaluate the South Simcoe Police Service's (SSPS) Crisis Outreach and Support Team (COAST), with the goal of assessing program successes and challenges so as to inform best practices for service delivery. To participate you must be an active duty police officer who has had some contact with COAST in the last 6 months.

This study involves one 1-2-hour interview that will take place in a mutually convenient, safe location. With your consent, interviews will be audio-recorded. Please note that audio-recording of the interview is a mandatory part of your participation. Once the recording has been transcribed, the audio-recording will be destroyed.

While it may not be possible to conceal the fact that you have participated in the study, and some people may be able to connect you to your specific interview responses, care will be taken to protect your identity in all presentations and publications emerging from this research. This will be done by keeping all responses anonymous and by not specifically naming the organizations involved in this research in presentations or publications. Attached you will find the interview questions we plan to ask you. Given what we've just said about risks to confidentiality, if you do not feel that you can provide candid responses to these questions, you may not want to participate in the study.

Participation in the study is entirely voluntary. In addition, you do not have to answer specific interview questions if those questions make you uncomfortable. Finally, you will have the right to end your participation in the study at any time, for any reason, including while the interview is taking place. Following the interview, you will have 7 days to withdraw your data if you wish to do so. If you choose to withdraw at any time, including within this 7- day period, all the information you have provided will be destroyed. You simply need to email me to let me know if you wish to withdraw your data from the study.

All research data, including audio-recordings and transcriptions of your interviews will be encrypted. Any hard copies of data (including any handwritten notes or USB keys) will be kept in a locked cabinet at Carleton University. Research data will only be accessible by the research team. 
The ethics protocol for this project was reviewed by the Carleton University Research Ethics Board, which provided clearance to carry out the research.

Should you have any ethical concerns with the study, please contact the REB Chair, Carleton University Research Ethics Board-B (by phone: 613-520-2600 ext. 4085 or by email: ethics@carleton.ca). For all other questions about the study, please contact the researcher.

If you would like to participate in this research project, please contact me at jamie.thompson3@carleton.ca.

Sincerely,

Jamie Thompson

CUREB Clearance \#: 111255 


\section{Appendix E}

\section{Informed Consent}

The information included in this form is intended to help you understand what we are asking of you so that you can decide whether you agree to participate in this study. As you read through this form, and decide whether to participate, please ask all the questions you might have, take whatever time you need, and consult with others as you wish.

\section{Project Title}

A qualitative evaluation of a co-responding mobile crisis intervention team in a small Canadian police service

\section{Name and Contact Information of Researchers}

The following people will be involved in this research project and may be contacted at any time:

Dr. Craig Bennell, Carleton University, Department of Psychology, Faculty of Arts and Social Sciences

Tel: 613-520-2600 ex. 1769

Email: craig.bennell@,carleton.ca

Jamie Thompson, Carleton University, Department of Psychology, Faculty of Arts and Social Sciences

\section{Tel:}

\section{Email: jamie.thompson3@carleton.ca}

Two additional research assistants may participate in the interviews: Tori Semple and Bryce Jenkins.

\section{Project Sponsor and Funder}

This project is funded through a grant from the Social Sciences and Humanities Council of Canada, which was awarded to Dr. Laura Huey at Western University. The title of the grant is

LEADS Agencies Canada (LEADS stands for Law Enforcement Advancing Data and Science).

\section{Carleton University Project Ethics Clearance}

This project was reviewed and cleared by the Carleton University Research Ethics Board (CUREB) B. Should you have any ethical concerns with the study, please contact the REB Chair, Carleton University Research Ethics Board-B (by phone: 613-520-2600 ext. 4085 or by email: ethics@carleton.ca). For all other questions about the study, please contact the researcher. Clearance \#: 111255 Date of Clearance: 


\section{What is the Purpose of the Study?}

This study will examine the South Simcoe Police Service's (SSPS) Crisis Outreach and Support Team (COAST), with the goal of assessing program successes and challenges so as to inform best practices for service delivery. The evaluation will involve interviews with COAST members, as well as front-line police officers in South Simcoe, senior leadership in the SSPS, Canadian Mental Health Association (Barrie), and York Support Services Network.

\section{Eligibility Criteria:}

To participate in this study, you must be an active duty police officer who has had some contact with COAST in the last 6 months.

\section{What will I be Asked to Do?}

If you agree to participate in the study, we will ask you to:

Take part in an interview with one of the researchers (listed above). The interview will take approximately 1-2 hours. All interviews will be audio-recorded (this is a mandatory part of your participation). Audio-recordings will be transcribed using the transcription service "Way With Word". All interviews will be conducted in person. The interviews can take place at one of the two South Simcoe Police Service locations, at the YSSN, at the CMHA (Barrie location), or at another location of your choosing.

\section{Risks and Inconveniences}

In general, we do not anticipate any significant risks to participating in this study. All study data will be de-identified, and the organizations involved in the project will not be specifically named in any presentation or publication. So, nobody other than the participating researchers will know your individual results. If quotes are used in presentations or publications, pseudonyms will be used and locations will be changed. However, given the small number of participants that will be interviewed for this study, it is possible that people within your organization will know you participated in the study and they may even be able to connect your interview responses to you. While we have been given assurances from your organization that your decision to participate or not will not affect you in any way, if you are concerned with providing candid responses to interview questions about the COAST program, you may want to decline the invitation to participate in this study. You can view the attached list of interview questions to help you make your decision.

\section{Possible Benefits}

You may not receive any direct benefit from your participation in this study. However, your participation may allow researchers to better understand the benefits and challenges of the COAST and whether this program is accomplishing what it intends to accomplish. Furthermore, your participation may allow researchers to inform best practices around the delivery of services to people experiencing crises. To the degree that the research improves the COAST, the community may experience benefits such as higher quality service from police officers and 
mental health professionals, increased diversion from the criminal justice setting, and more appropriate community referrals for mental health issues. We plan on sharing the results of this research with your organization and will request that they share it with you so that you can learn what we discover.

\section{Compensation/Incentives}

You will not be paid or compensated for your participation in this study.

\section{No Waiver of Your Rights}

By signing this form, you are not waiving any rights or releasing the researchers from any liability.

\section{Voluntary Nature of Participation and Right to Withdraw}

Your participation in this study is entirely voluntary and, as indicated above, a decision not to participate will not be used against you in any way.

You can decide not to answer any specific interview questions(s) if they make you uncomfortable.

You may also withdraw from the study at any point in time throughout the interview. If you withdraw your consent during the course of the interview, all information collected from you before your withdrawal will still be used, unless you request that it be removed from the study data.

After the interview, you may request that your data be removed from the study and deleted by notice given to the lead researcher (Jamie Thompson; see email above) within 7 days after your completion of the interview.

\section{Confidentiality}

As indicated above, while we will take great care to protect your identity by not attaching your name to your responses in any reports, publications, or presentations, given the small number of participants that will be interviewed for this study, it may not be possible to conceal the fact that you have participated in the study. Some people may also be able to determine your identity from your responses to interview questions.

We will remove all identifying information from the study data once all audio-recorded interviews have been transcribed and verified. All data will be kept in a password protected file on a secure computer. The data will only be accessible to researchers who are involved in the study. Note that research records may be accessed by the Carleton University Research Ethics Board in order to ensure continuing ethics compliance.

\section{Data Retention}

After the study is completed, your de-identified data will be retained for a period of six (6) years and then destroyed. Within the six-year period, your de-identified data may be used for future 
research. Electronic data will be stored in a password protected file on a secure computer at Carleton University. Consent forms will be kept in a locked office at Carleton University. Data retention is based on the American Psychological Association guidelines for publication, which indicate data should be kept for a period of six years after publication.

\section{Statement of Consent}

I voluntarily agree to participate in this study.

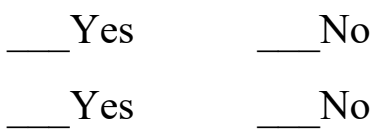

I agree to be audio recorded.

(Note: Audio recording of the interview is a mandatory part of participation.)

I understand that confidentiality can not be guaranteed.

Yes

Date

\section{Research team member who interacted with the participant}

I have explained the study to the participant and answered any and all of their questions. The participant appeared to understand and agree. I provided a copy of the consent form to the participant for their reference. 


\section{Appendix F}

\section{Debriefing Form}

\section{Project Title}

A qualitative evaluation of a co-responding mobile crisis intervention team in a small Canadian police service

\section{Name and Contact Information of Researchers}

The following people were involved in this research project and may be contacted at any time if you have questions or concerns:

Dr. Craig Bennell, Carleton University, Department of Psychology, Faculty of Arts and Social Sciences Tel: 613-520-2600 ex.1769 Email: craig.bennell@,carleton.ca

Jamie Thompson, Carleton University, Department of Psychology, Faculty of Arts and Social Sciences Tel: Email: jamie.thompson3@,carleton.ca

\section{Project Sponsor and Funder}

This project is funded through a grant from the Social Sciences and Humanities Council of Canada, which was awarded to Dr. Laura Huey at Western University. The title of the grant is LEADS Agencies Canada (LEADS stands for Law Enforcement Advancing Data and Science).

\section{Carleton University Project Ethics Clearance}

This project was reviewed and cleared by the Carleton University Research Ethics Board (CUREB) B (Clearance \# 111255).

\section{What are we trying to learn in this research?}

This study is examining the South Simcoe Police Service's (SSPS) Crisis Outreach and Support Team (COAST), with the goal of assessing program successes and challenges so as to inform best practices for service delivery.

\section{Why is this important to scientists or the general public?}

Previous research has shown that programs such as the COAST can be beneficial for both members of the public (i.e., service users) and police officers. However, research on these programs in Canada is lacking. We hope that the results of this research can be used to improve the COAST program. Some of the benefits of such improvements might be: higher quality service from police officers and mental health professionals for people people experiencing crises in your community, increased diversion from the criminal justice setting, and more appropriate community referrals for mental health issues.

\section{Where can I learn more?}

Below is a list of resources should you wish to learn more about this topic:

Crisis Outreach and Support Team: A program of St. Joseph's Healthcare, Hamilton. https://coasthamilton.ca/ 
St Joseph's Healthcare Hamilton: COAST (Crisis Outreach and Support Team).

https://www.stjoes.ca/health-services/mental-health-addiction-services/mental-healthservices/coast

A Study of How People with Mental Illness Perceive and Interact with the Police, Mental Health Commission of Canada.

https://www.mentalhealthcommission.ca/sites/default/files/Law_How_People_with_Mental_Illn ess_Perc eive_Interact_Police_Study_ENG_1_0_1.pdf

Co-responding Police Mental Health Programs: A review. Shapiro, G.K., Cusi, A., Kirst, M. et al. Adm Policy Ment Health (2015) 42:606. https://doi.org/10.1007/s10488-014-0594-9

\section{What if you feel distress following the interviews?}

If you feel any distress or anxiety after participating in this study, please feel free to contact the Telecare Distress Line of Greater Simcoe at 705-325-9534 or 705-726-7922

(http://telecaredistressline.com/) or the York Support Services Network Crisis Line at 1-855-3102673 (https://www.yssn.ca/).

\section{What if I have questions later?}

If you have any remaining concerns, questions, or comments about the study, please feel free to contact Jamie Thompson (Principal Investigator), at: jamie.thompson3@carleton.ca (

), or Dr. Craig Bennell (Faculty Sponsor), at: craig.bennell@carleton.ca (613-520-2600, ext. 1769).

\section{Withdrawal Procedures}

Remember that you are allowed to withdraw from this study within 7 days of your interview. If you withdraw, all of your data will be deleted. If you wish to withdraw, please contact Jamie Thompson to let her know at jamie.thompson3@carleton.ca or

\section{Thank you for participating in this research!}




\section{Appendix G}

\section{Quality control checks for qualitative interviews}

The objective of this study was to examine the South Simcoe Police Service's (SSPS) Crisis Outreach and Support Team (COAST), with the goal of assessing program successes and challenges so as to inform best practices for service delivery. The study consisted of interviews with COAST members, SSPS frontline officers, and senior leaders in the SSPS, Canadian Mental Health Association (Barrie), and York Support Services Network.

The following analysis focuses on five major areas and their subsequent themes. The themes identified are not exhaustive to everything that was discussed during the interviews, more so focusing on topics in which most participants had talked about.

Below you will find a condensed version of the results to see if what I have highlighted is consistent with your perspective. Once you have read through the analysis, please let me know if there are any areas you feel I have not addressed, keeping in mind the goal of the study. At the end of the document is a map that provides an overview of the themes.

Note: The term service users refer to individuals in crisis who have come into contact with the SSPS and/or the COAST.

\section{Need for the COAST}

The analysis showed that there was a need for the COAST in South Simcoe. Four main themes were identified:

1) Contact with police: SSPS are often the first point of contact when individuals are experiencing mental health related crises. This was often associated with the fact that the police are the only entity that is available 24.7 .

2) A lot of mental health calls: SSPS receive many mental health and crisis related calls and this number seems to be increasing.

3) Insufficient access to services: There is a lack of mental health services available in the communities of Innisfil and Bradford. In addition, there are barriers in accessing the limited services that are available (e.g., transportation).

4) Frontline officers not equipped: Frontline officers lack the necessary training, education, and knowledge to appropriately handle mental health and crisis related calls.

a. Unnecessary apprehensions: From a liability standpoint, frontline officers are more likely to apprehend individuals in crisis under the Mental Health Act.

\section{COAST Activities}

One of the goals of this study was to identify how the COAST operates. Six major activities were identified:

1) Training: The COAST provides both formal (i.e., organized information sessions) and informal (i.e., debriefing with officers after a crisis call) training to frontline officers. 
There was an indication that more training could be provided regarding the goals of the COAST and how the program operates.

2) Follow-ups: The COAST conducts follow-ups with service users who have had an encounter with the police. Follow-ups were recognized as essential in reducing future contact with the police from the same individuals.

3) Connect to resources: The COAST refers services users to various resources within the community and help to facilitate the connection between service users and the available resources. The COAST has extensive knowledge of the available resources.

4) De-escalation: The COAST is intended to de-escalate crisis situations with the goal of avoiding the emergency department.

5) Emergency Department diversions: The COAST is geared towards emergency department diversion and keeping individuals out of the hospital, avoiding apprehensions where unnecessary. Service users are better supported in the community.

6) Program monitoring: The COAST members collect data to keep track of the program to support the need for the COAST and to also reveal areas in which the program can improve.

\section{COAST Goals}

The analysis showed five major goals of the COAST:

1) Free up frontline officers: The COAST helps to alleviate frontline officer resources so that officers can attend other calls for service. Crisis calls can be very time consuming for frontline officers.

2) Support client and family: The COAST provides service users and their families with an enhanced level of support.

3) Reduce recidivism: Since the implementation of the COAST, SSPS are receiving less reoccurring calls from the same individuals. This was often associated with the fact that the COAST conducts follow-ups with service users and connects these individuals to resources in the community.

4) Increase officer awareness: Frontline officers feel as though the COAST has helped them learn how to respond more appropriately to crisis calls and has increased officers' knowledge of the available resources in the community.

5) Building relationships: The COAST has improved the working relationship between police and mental health service providers (i.e., YSSN, CMHA, local mental health resources). The COAST has resulted in a more collaborative approach between the police and mental health service providers who have traditionally worked as separate entities.

\section{Benefits of the COAST}

There were six benefits of the COAST program that were identified:

1) Support frontline: The COAST provides support to frontline officers in the sense that it gives officers an additional tool to utilize when responding to crisis calls. Officers are able to call the COAST for advice or resource information when the COAST is unable to attend a live call. 
2) Officer and crisis worker: The presence of the crisis response worker brings a certain level of expertise to a live crisis call and creates a more personable interaction with service users.

3) Services getting used: Mental health resources and services providers are now seeing greater utilization of these services due to the increased number of referrals via the COAST.

4) Decriminalization: The implementation of the COAST has resulted in the decriminalization of individuals experiencing mental health related crises. The plain clothed officer and the use of an unmarked police vehicle allows for more discretion when attending crisis calls.

5) Provide better service: The COAST provides a better service to individuals in crisis beyond the traditional police response due to their enhanced level of knowledge and training in mental health. In addition, the COAST can take the extra time to provide support to service users by conducting follow-ups.

6) Bridge gap: The COAST helps to bridge the gap between police and mental health care as often the available community resources are unknown to service users. In addition, the COAST also serves as a support service itself due to the lack of resources in the community.

\section{COAST Challenges}

The analysis identified four major challenges associated with the COAST:

1) Coverage: There is a lack of coverage of the COAST program, specifically a lack of availability for live crisis calls. Lack of coverage is typically associated with limited resources (i.e., one COAST officer and a few crisis response workers).

2) Funding: The COAST program has limited funding which is often associated with the lack of resources for the COAST program.

3) Program awareness: There is a lack of awareness among the general public in regard to the existence of the COAST program which may hinder accessibility to the program to both individuals and local organizations (i.e., mental health services).

4) Relationship with hospitals: The relationship between the COAST, and SSPS more generally, with the local hospitals has been an on-going challenge. There seems to be a lack of understanding and perhaps a lack of respect between the police and the healthcare system. 


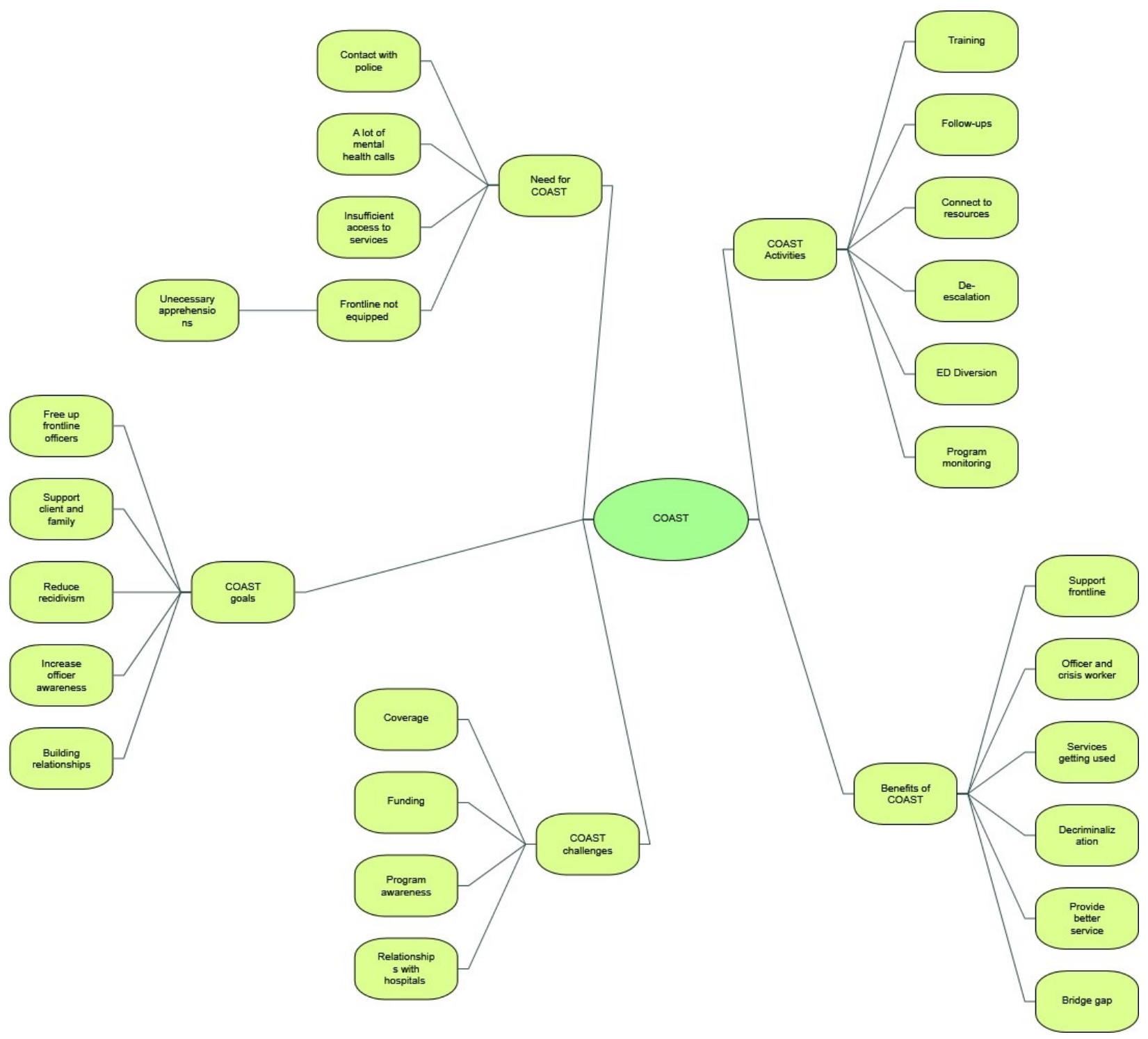




\section{Appendix H}

\section{Audit trail for the interview process}

November $4^{\text {th }}, 2019$ : Note for description of the research site: It took me approximately 25 minutes to drive from one SSPS station to the other.

November $5^{\text {th }}, 2019$ : Added “when crisis calls occur" to question number $6 \mathrm{~b}$ for frontline officers.

November $5^{\text {th }}, 2019$ : Some frontline officers required prompting for question 9 as it seemed they did not understand the question. Most officers were fine to answer without requiring prompting.

November $6^{\text {th }}, 2019$ : There were two particularly negative cases (i.e., interviews) involving two frontline officers. Throughout their interviews they seemed be very frustrated with the fact that the COAST is rarely available for live calls. Many frontline officers did mention this as a challenge, but these two cases stood out as having a negative tone throughout the interview while the other officers seemed to be more positive.

\section{Audit trail for the analytical process}

February $15^{\text {th }}, 2020$ : some of the common topics based on my recollection of the interviews without reviewing the transcripts included:

- Coverage was lacking

- Relationship with hospitals is challenging

- Lack of resources in the community

- Increase in mental health calls

- Frontline officers tend to apprehend

- COAST helps alleviate frontline resources

- Destigmatization/Decriminalization of mental health

- Emergency Department Diversions

February $16^{\text {th }}, 2020$ : To familiarize myself with the data I listened to each interview while following along with the transcripts. There were some errors in the transcriptions mostly relating to acronyms or the name of specific community resources. Other errors included spelling or grammatical errors. All errors were corrected. A copy of both the original and corrected transcripts were kept.

March 15 th 2020 : I've now completed the initial coding process for all interviews using in vivo coding (initial coding process completed in word using comments). 
April $4^{\text {th }}, 2020$ : The initial codes have now been identified and collated. Groupings of similar codes have been assigned a temporary code name for the purpose of re-coding the interviews using NVivo.

April 17 $7^{\text {th }}$ 2020: All interviews have now been re-coded in NVivo using the temporary code names. The coding analysis has revealed five main themes. Codes (i.e., sub-themes) have been organized within the five identified themes.

May $2^{\text {nd }}, 2020$ : I have now gone through all data extracts for each identified sub-theme to ensure that the theme truly reflects the data. Sub-themes have also been assigned a new name to more accurately reflect the words used by participants.

May $13^{\text {th }}$, 2020: Due to the large scope of the study, sub-themes in which all three participant groups did not speak on were removed from the final collection except for the sub-theme "Building relationships".

May $26^{\text {th }}, 2020$ : When going through the final list of themes, I realized that within the theme "Frontline not equipped", several participants had specifically mentioned the tendency for frontline to apprehend. Since ED diversion is clearly an important piece for the COAST, I decided to create the sub-theme "Unnecessary apprehensions". 


\section{Figure 3}

The initial thematic map. Sub-themes identified in orange were removed from the final collection of themes.

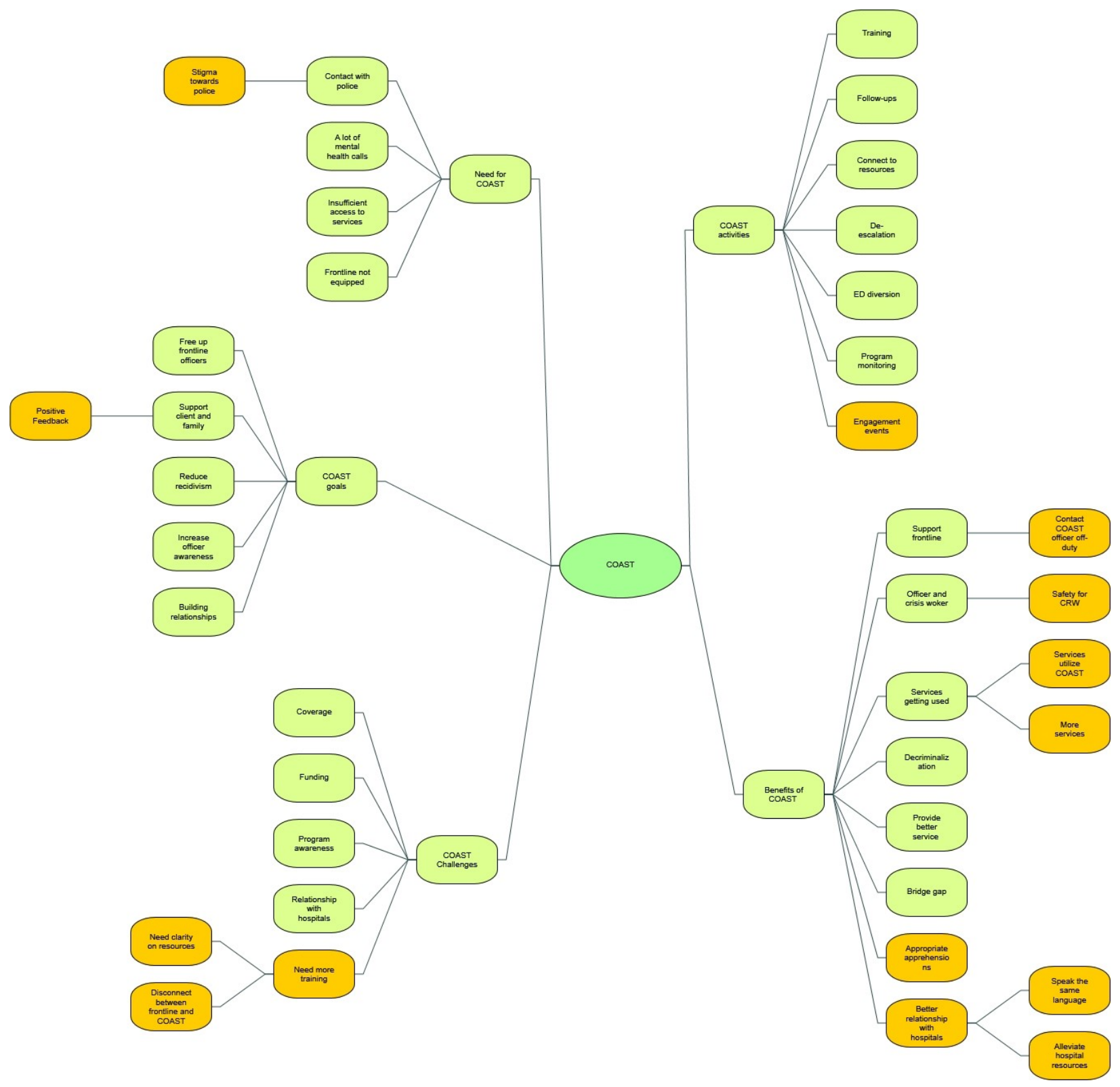




\section{Figure 4}

The final thematic map.

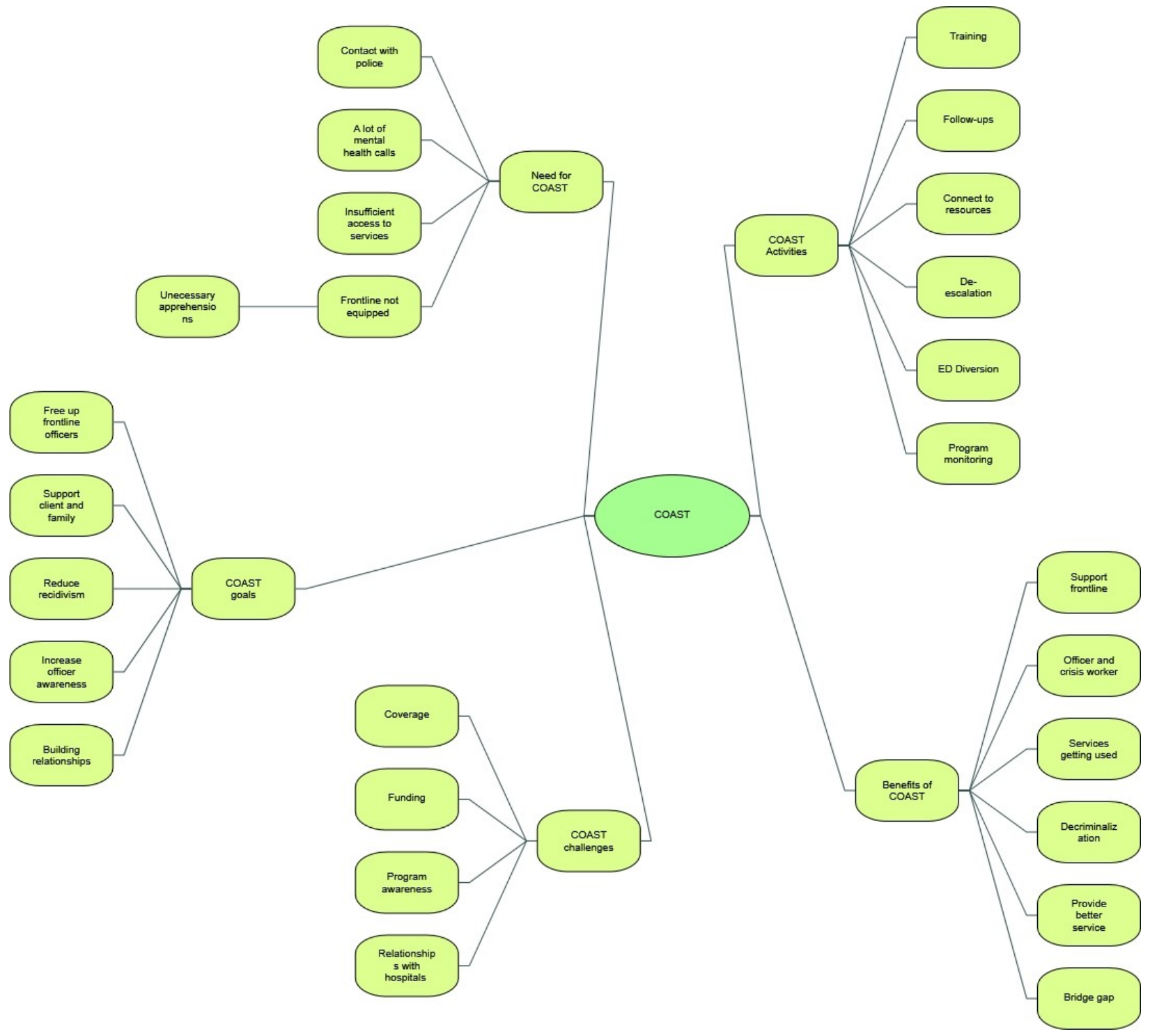

